\title{
LA CONSERVACIÓN DE LA ARQUITECTURA Y LOS ESPACIOS CULTURALES A PRINCIPIOS DEL SIGLO XXI. NUEVOS INSTRUMENTOS PARA EL RECONOCIMIENTO DEL VALOR Y PARA LA RESTAURACIÓN DEL PATRIMONIO CULTURAL ITALIANO
}

\author{
ANTONIO PUGLIANO \\ Università Roma Tre
}

En los inicios del siglo XXI, en el ámbito italiano se produjo la maduración de algunas interpretaciones sobre la definición «brandiana » de la restauración. Con el objeto de respaldar la potencialidad operativa de su método, se afirmó que el reconocimiento del valor constituye la acción fundamental de la restauración arquitectónica. Los objetos artísticos y culturales no deben ser considerados únicamente como expresiones simples y aisladas, sino vinculados a su contexto cultural de origen, así como con las costumbres e intenciones que los han determinado. El reconocimiento, implica recurrir a formas organizadas de conocimiento, y entre ellas, la Catalogación de los Bienes Culturales Arquitectónicos demuestra la mayor potencialidad operativa. La Catalogación permite recuperar lazos con la historia de la tutela y desplegar instrumentos y metodología científica adecuados para la práctica de la restauración, asociada a la valorización de la arquitectura y de los espacios culturales.

Arquitectura, catalogación, valor patrimonial.

\section{Palabras clave}

\section{Abstract}

In the prime twentyfirst century, occurred in Italy the maturation of some recent interpretations of the Cesare Brandi's definition about restoration, with the aim to develop the operational potential of his method, saying the recognition of value as a fundamental action of architectural restoration. The artistic and cultural objects can not only be considered simple and unique expressions, but in its original cultural context, related to customs and the intentions that have been determined. The recognition involves using organized forms of knowledge, including the Cataloging of Cultural Architectural goods demonstrates the greatest potential operational. The Cataloging to retrieve links to the history of the guardianship and deploy instruments and scientific methodology suitable for the practice of restoration associated with the appreciation of architecture and cultural spaces.

Architecture, cataloging, heritage value.

\section{Keywords}

\footnotetext{
Architecture, cataloging, heritage value.
} 


\section{Introducción}

En Italia, durante la primera década del siglo XXI, se ha practicado la tendencia de madurar algunas de las recientes interpretaciones de la definición "brandiana" de restauración . Se trata de desarrollar la potencialidad operativa de dicho método, que deriva de tal definición, una vez se haya identificado el reconocimiento del valor como acción que caracteriza a la restauración, y además se haya producido la formulación de un juicio crítico y operativo, como consecuencia del reconocimiento del valor. El panorama legislativo Italiano en lo que respecta a los Bienes Culturales, cuya reforma se efectúo a finales del siglo $\mathrm{XX}$, se ha hecho eco de dicha interpretación definiendo con precisión y de manera unívoca los conceptos de Conservación, Tutela, Restauración, además del de Valorización ${ }^{2}$, transformándolos en modelos de comportamiento. La primera y fundamental adquisición normativa radica, en que la Conservación no consiste en una categoría operativa, sino en una finalidad, y ésta se alcanza a través de la Restauración. No existe por lo tanto, ninguna buena restauración que no sea conservativa, con lo cual, únicamente queda por comprender qué elementos deben conservarse en relación con la totalidad del objeto, sea material o inmaterial. En cada obra a conservar, debe individualizarse con mucha atención el ámbito en el que se aplica la restauración: el argumento; se deben reconocer las expresiones de los valores y significados dignos de ser transmitidos al futuro. Deben seleccionarse y contribuir de un modo apropiado a su legibilidad, de manera que la obra restaurada, y por tanto interpretada, exprese la información cultural que atesora. No puede concebirse una buena restauración que no comprenda la valorización del objeto como acto indispensable.

Por lo tanto, el acto de reconocer se convierte en una acción fundamental de la restauración de la Arquitectura, así como motor de su operatividad técnica. Sin embargo, reconocer, significa haber conocido: no se puede reconocer aquello que es ignorado $u$ olvidado. Reconocer, por lo tanto, es una acción análoga a recordar, a evocar, o también asistir a su nueva manifestación; al aparecer en nuestra con ciencia como una experiencia ya realizada que se torna habitual y típica, permanece impresa en forma de memoria proclive a ser evocada. En consecuencia, los objetos artísticos y culturales no pueden ser considerados únicamente como expresiones aisladas y singulares, sería limitativo. Por el valor de su contribución a la cultura actual, sería más adecuado considerarlos representativos de las costumbres y de la ideas enraizadas en su contexto cultural de origen. Las actividades para conocer y reconocer necesitan el ejercicio de un método basado en el uso de instrumentos apropiados. En resumen: el reconocimiento "Brandiano", obliga a recurrir a formas organizadas de conocimiento, y en el siguiente texto se describen, auxiliado con ejemplos, algunos logros obtenidos como resultado de esta consideración.

${ }^{1}$ Escribe Brandi en la Teoría: "La restauración, constituye el momento metodológico del reconocimiento de la obra de arte, en su consistencia física y en doble polaridad estética e histórica, con una visión hacia el futuro" Cfr. BRANDI C: Teoria del Restauro, Torino, Einaudi, 1.977, Pag.6: cap.1 "El concepto de la Restauración”.

${ }^{2}$ El concepto de valorización al que se hace referencia, proviene del Código de los Bienes Culturales y del Paisaje, promulgado por El Consejo de Ministros el 16 de Enero de 2.004 y que comenzó a regir el 1 de mayo de 2.004. La valorización "consiste en el ejercicio de las funciones y en la disciplina de las actividades dirigidas a promover el conocimiento del patrimonio cultural asegurando las mejores condiciones de utilización y fruición pública del patrimonio mismo. Esta comprende también la promoción sustento de las intervenciones de conservación del patrimonio cultural". Cfr. Primera parte, disposiciones generales artículo 6, Valorización del Patrimonio Cultural.

Los actores de la valorización constituyen una sociedad heterogénea confirmada por personas públicas y privadas que trabajan bajo el patrocinio del Ministerio y de las entidades públicas territoriales; estos se encargan de coordinar, armonizar e integrar las actividades de valorización de los bienes públicos, según los principios del Código al que deben ceñirse las Regiones en el ejercicio de su propio poder legislativo. Naturalmente "la valorización debe actuar en forma compatible con la tutela de tal forma que no perjudique las exigencias", y ello es un requisito ineludible para activar esta correlación entre otras amparadas y sostenidas por el Estado, con las personas privadas independientes o asociadas, y que están empeñadas en los programas del Patrimonio Cultural. 


\section{Formas organizadas para el conocimiento. Potencialidades operativas en la catalogación de Bienes Culturales Arquitectónicos}

En los últimos años, Italia se ha comprometido a renovar las relaciones con la Historia de la Tutela del Patrimonio Cultural, a través del desarrollo de una metodología actualizada para el conocimiento científico de las diferentes expresiones artísticas y culturales (materiales $e$ inmateriales), individualizando los instrumentos de conocimiento necesarios para poner en práctica la conservación a través del Catálogo de los Bienes Culturales. El Catálogo constituye un repertorio racional y estructurado de información, bastante útil para documentar las características distintivas de los objetos que son susceptibles de conservación. Precisamente, la conservación de tales características distintivas que podemos denominar identificativas, es lo que se persigue a través de la tutela y de la restauración. Las características distintivas son consideradas el argumento de la Conservación y el campo de aplicación de las intervenciones de restauración a nivel técnico, porque de éstas dependen la atribución del valor y significado al objeto.

No podía ser de otra forma, históricamente, el registro de los objetos reconocidos como expresión particular del arte y de la historia, ha determinado siempre el proceso de formación de la identidad cultural de una comunidad, pueblo o nación, y la voluntad de identificar, describir y difundir el conocimiento racional de las obras con valor, ha acompañado el proceso histórico de formación del concepto de Conservación. Las formas actuales de Catalogación derivan de experiencias precedentes, en alguna medida recientes: basta pensar en la legislación de la República de Venecia, que en el año 1.773 por disposición del Consejo de los Diez, con el objeto de obtener la "preservación y mantenimiento (....) de los cuadros más representativos, obras de célebres autores existentes en las iglesias, escuelas, monasterios y otros lugares de la ciudad y de las islas cercanas", disponía de un "catálogo" con la descripción de dichas obras. Al conjunto de experiencias italianas, que deben considerarse fundacionales para la formación del enfoque moderno -teórico y operativo- para el conocimiento científico de las expresiones de arte y cultura, pertenecen el conocido edicto del Cardenal Pacca y su respectiva reglamentación, promulgados entre abril de 1.820 y agosto de 1.821. En este corpus normativo se trazaron los principios de información y finalidad del catálogo moderno. Se trataban los requisitos prácticos para identificar y reconocer las obras; la necesidad de validez y veracidad de los datos; la posibilidad de actualización y control de los mismos, así como la participación de los distintos conceptos en la formación de la descripción, de las generalidades de la norma ${ }^{3}$. El escenario normativo Italiano entre finales del siglo XVIII y la primera mitad del siglo XIX mostraba realmente, de manera oportuna y con rigor, el sentimiento común de otras naciones europeas. Pensemos en las iniciativas francesas puestas en marcha con la Convención Nacional (1.793/95), que fueron encaminadas a contener el vandalismo revolucionario. Más tarde, a nivel empresarial, se originó el deterioro de los vestigios góticos, a pesar de que la intención fuese garantizar la conservación de las obras histórico artísticas a través de su conocimiento, la comprensión de su valor y el ejercicio de la restauración. El punto crucial de este proceso normativo, encaminado a la protección y a la conservación de los objetos histórico artísticos del pasado, era la institución del Inventario de los bienes adquiridos por el Estado: se situaba así la Nación a la cabeza de la tutela de las obras de arte, a las que se les reconocía un papel patriótico y educativo, el único más acorde con la formación de los "espíritus libres".

Desde estas primeras iniciativas hasta la definición de la normativa actual, basada en la disposición constitucional ${ }^{4}$, la actividad de catalogación en Italia ha seguido la estructuración

\footnotetext{
${ }^{3}$ Para un análisis más profundo de la evolución histórica de la clasificación en Italia ver: NEGRI. F. Arnoldi: II Catalogo dei Beni Cuturali (Principi e teniche di indagine), Roma 1.981, y para profundizar sobre el argumento tratado en esta parte del texto véase: SATTALINI, F.: "Introduzione circa la documentazione, dell'Archittetura e i modi per la sua catalogazione" en: PUGLIANO A.:,Il riconoscimento, la documentazione, il catalogo dei Beni archittetonici. Elementi di un constituendo Thesaurus utile alla conscenza, alla tutela, alla conservazione del'Archittetura. 2 vol. Roma, Mibac- ICCD, Prospettive, 2.009, pagg. VII-XIII.

${ }^{4}$ La Constitución Italiana (Articulo 9) prevé la promoción del desarrollo de la cultura, de la investigación científica y técnica, la protección del patrimonio histórico, artístico y del paisaje.
} 

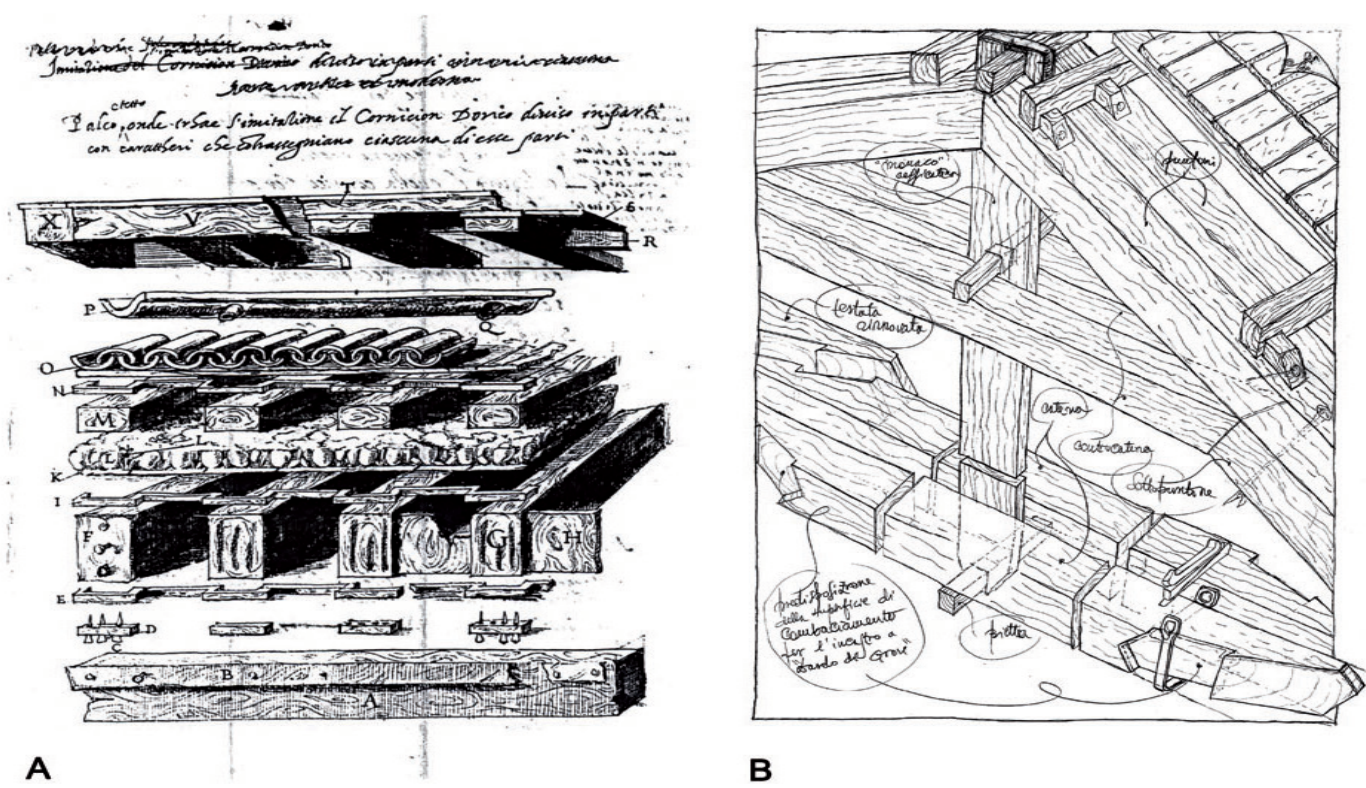

B

Fig. 1. (A). Fuentes indirectas para la historia de las técnicas constructivas tradicionales. Descripción de las "reglas del arte" para la realización de una cornisa dórica en mampostería y madera. SPINI, G.: I Tre Primi Libri di Gherardo Spini sopra l'Instituzioni de Greci et Latini Architettori. Intorno agl'ornamenti che convengono a' tutte le fabbriche che l'Architettura compone. Venezia, 1568/69. [Manuscrito conservado en la Biblioteca Nazionale di San Marco, Venezia, coll. :MSS.ITALIANI,Cl.4, n38,5543].

(B)Necesaria historia de las técnicas constructivas tradicionales para las intervenciones de restauración filológica. Descripción de las intervenciones de sustitución de las extremidades desgastadas del tirante de las cerchas del 1400 presentes en la Iglesia de S. Pietro in Vincoli (Roma). Las partes reconstruidas se pueden unir a las preexistentes por medio de la reproducción de antiguos empalmes de "Rayo de Júpiter". PUGLIANO, A.: Studi preliminari alla redazione del Manuale del Recupero del Comune di Roma, 1995

de los conceptos de Bienes Culturales, Tutela, Conservación y Restauración, cumpliendo un papel fundamental como punto de partida en el proceso conservativo, y asimismo, como mínimo común denominador de la tutela, con ocasión de la coordinación de programas e iniciativas que, en el sector de los Bienes Culturales, formulan en el territorio las diversas Administraciones del Gobierno ${ }^{5}$. En conclusión, resulta indispensable proteger y conservar 3-)

${ }^{5}$ Conferencia de Atenas de 1.931 y "Carta d'Atene del Restauro dei monumenti" ( Cap. VIII, puntos 1-2-

-“Carta Italiana del Restauro" redactada por el Consejo Superior para la antigüedad y bellas artes de 1.931."Carta di Venezia" 31 Mayo de 1.964, en donde se habla por primera vez de la protección del ambiente y de los Centros Históricos

Documento de la Commissione Franceschini publicado en 1.967, donde se define el bien cultural como "Testimonianza materiale avente valore di civilitá". La Convención Internacional: La Haya 1.954 para la protección del patrimonio en caso de guerra, Londres 1.969 para la protección del patrimonio arqueológico, Paris 1.970 protección a las exportaciones, Paris 1.972 protección de patrimonio Cultural y Natural del mundo, Granada 1.985 salvaguardia del patrimonio Arquitectónico, Estrasburgo 1.985 sobre los atentados contra los bienes Culturales-UNESCO junio de 1.964 " Rapporto preliminare...”. UNESCO Conferencia General Noviembre 1.964 sobre las medidas a tomar para impedir la exportación, la importación y el traspaso ilícito de Bienes Culturales. -Congreso de Europa 1.966 "Risoluzioni sui criteri e metodi per un inventario delle località e dei complessi storico-artistici” 
los testimonios artísticos y culturales, y en cualquier caso, es necesario su conocimiento de un modo científico. Los objetos materiales individuales no son diferentes a los que forman parte de su contexto global, es decir, el método debe aplicarse desde la escala del objeto aislado, hasta la del paisaje y el territorio intervenido por el hombre. En este sentido, el catálogo se convierte en un servicio público, encaminado a otorgar a la comunidad un soporte adecuado para el conocimiento de su propio patrimonio cultural.

Al hilo de lo anterior, al Istituto Centrale per il Catalogo e la Documentazione, creado en Italia en el año 1975, dependiente del recién creado Ministero per i Beni e le Attività Culturali, le fue asignada la labor de elaborar una metodología general para la catalogación territorial, promover y coordinar las actividades ejecutivas de catalogación y documentación y estructurar el Catálogo General de los Bienes Culturales de interés arqueológico, históricoartístico, arquitectónico y ambiental.

\section{Los manuales de Recuperación y la renovada "cultura del proyecto" en la restauración.}

De acuerdo con lo anteriormente expresado, la práctica de la conservación de los bienes arquitectónicos, impone ejercer coherentemente, un método sustentado por instrumentos apropiados.

Actualmente, los investigadores y las instituciones encargadas de la tutela, se ocupan de la elaboración de instrumentos culturales y también de realizar ensayos metodológicos. Esta óptica disciplinar debe su origen a las experiencias maduradas en Italia por los restauradores de arquitectura, arquitectos e ingenieros, a partir de la última veintena del siglo pasado.

A causa de la urgente situación derivada tras el terremoto de Irpinia, ocurrido en los años ochenta del siglo veinte que fue nefasto para el Sur de Italia, el Ministerio de Bienes Culturales y Ambientales ha promovido notables iniciativas acerca de la prevención sísmica. ${ }^{6}$ Por otra parte, en los últimos treinta años, ha tomado fuerza la tendencia a investigar la identidad entre cultura bumanistica y cultura científica, diseñando una metodología dirigida a la aplicación de los postulados fundamentales de la teoría de la restauración, pero enfocados al aspecto estructural.

Se ha tratado de considerar las obras arquitectónicas del pasado como organismos vivos cimentados sobre su fisonomía arquitectónica y sus razones constructivas [fig.1a]. Esta consideración ha llevado a recurrir a los instrumentos de la historia y de la filología, inclusive en la práctica eminentemente científica y técnica. Por lo tanto, los responsables del desarrollo del proyecto, empezaron a prestar especial atención a la interpretación tipológica de la arquitectura y de los elementos materia les que la componen, documentando los objetos reales con información procedente de la investigación histórica en archivos, que se configuraban como modelos explicativos con un léxico constructivo ya no tan usual. Asimismo, se ha intentado re-componer de un modo eficaz el lenguaje de la regla del arte tradicional, que

\footnotetext{
${ }^{6}$ Con esto se refiere a la actividad del Ministero Per i Beni e la Attività Culturali -Ufficio Centrale per i Beni Archeologici Architettonici Artistici e Storici -Comitato Nazionale per la Prevenzione del Patrimonio Culturale dal Rischio Sismico, del desaparecido Prof. Romeo Ballardini, entre los años 1.985 y 1.997. Dicha actividad está documentada en GUCCIONE, M.: (a cura di): "La Protezione del Patriminio Culturale. La Questione Sísmica. Linee di sviluppo della ricerca universitaria, obiettivi e aree di integrazione per i nuovo programmi scientifici, proposte normative", Actas del seminario Nacional de estudio, Roma, Abril 1.997.

También, las actividades del Istituto Centrale per il Restauro, con la dirección de Giovanni Urbani, en el contenido del Proyecto Terminado Geodinámica de CNR, documentado en BALDI, P. MICHELI, M.P., CORDARO, M., MAZZONE, B., SACCO, F.: "La protezione del Patrimonio Monumentale dal Rischio Sismico. Termini del problema", Catálogo y actas de la exposición, ICR. Roma, 1.983.

${ }^{7}$ Ministero Per i Beni e la Attività Culturali-Ufficio Centrale per i Beni Archeologici Architettonici Artistici e Storici-Co- mitato Nazionale per la Prevenzione del Patrimonio Culturale dal Rischio Sismico. Línea de investigación 4.1.1. Tecniche premoderne di prevenzione sísmica. Studio Storico, rilievi, modellazioni in Lazio, Abruzzo, Umbria, Irpinia. Dirección: P. Marconi. Coordinación: A. Pugliano. Investigación: G. Cangi, G. Cancelli, F. Giovanetti, F. Pompozzi, V. Sereni. Universi- dad de Roma "Sapienza", Facultad de Arquitectura, Departamento ITACA (1.985 - 1.997).
} 
aunque olvidado precipitadamente como si de una lengua muerta se tratase, en realidad, sus preceptos se encuentran tan difundidos, que presiden la realidad cultural y material de buena parte del patrimonio construido, y especialmente, en lo que respecta a la arquitectura de calidad extendida por el territorio nacional.

Una primera manifestación de este renovado acercamiento a la conservación de la arquitectura de interés histórico, artístico y antropológico, son los Manuales de Recuperación, los cuales evidencian la madurez alcanzada en el ámbito teórico abordado anteriormente y constituyen testimonios del avance de la investigación sobre las herramientas culturales enfocadas al proyecto. Precisamente, a estos productos culturales se debe el hecho que, actualmente, el proyecto de restauración arquitectónica y urbana se oriente cada vez más a lograr la compatibilidad filológica y física entre las nuevas intervenciones y los elementos preexistentes, considerando la "economía" como sinónimo de perdurabilidad y sostenibilidad de la obra restaurada. Los Manuales de Recuperación se dedican a analizar las técnicas de construcción tradicionales en diferentes lugares, a través del estudio tecnológico de modelos seleccionados por su expresiva tipología. De estas investigaciones, se extraen las directrices adecuadas para poder llevar a cabo intervenciones de restauración filológicamente coherentes con el entorno preexistente, además de ser mecánicamente eficaces [fig. 1b]. La divulgación de los contenidos de los mencionados estudios, confirma que la labor de los artífices de la restauración arquitectónica, se extendió a la intervención en las fábricas desde el punto de vista de la Firmitas, y por tanto, se amplía a todo aquello que concierne a la restauración filológica de la materia, que constituye la estructura de los edificios. No podía ser de otra forma, la cultura de la Restauración en Italia logró un cambio, superando la tradicional interpretación normativa de la Restauración del Arco de Tito, dirigida por Boito a fines del siglo XIX, la cual generalizó los criterios de reconocimiento y diferenciación, con el fin de valorizar la materia auténtica. No obstante, algunos historiadores y teóricos del restauro, después de casi un siglo, continúan oponiéndose y plantean una interpretación diferente, aunque legítima y bien fundamentada. Consideran este episodio, fruto de una mera oposición (propia del siglo XIX), entre actitudes de tipo filológico, destinadas a abordar la restauración de los monumentos, y una actitud emocional, perceptiva y sensible a la restitución estética de las ruinas. Si observamos por ejemplo, las interpretaciones de Quatremere De Quincy y Stendhal acerca del restauro "valadieriano" del Arco de Tito", se infiere que el primero estaba de acuerdo en la necesidad de realizar una reintegración de la arquitectura "domiciana", que expresara el significado global de la obra según el criterio neoclásico: a través de la imitación. Por el contrario, Stendhal se lamentaba de la pérdida que supondría no mantener el monumento en su condición de documento y testigo del trascurso del tiempo, y por tanto, del desarrollo de la historia. Remitiéndonos a lo anteriormente expuesto, encontraríamos una primera reconsideración de la prioridad de conservar la autenticidad material, sobre otros significados reconocibles en la arquitectura histórica.

En los años noventa del siglo XX, Raymond Lemaire proporcionó una significativa contribución al tema, tratando la autenticidad formal y la autenticidad histórica y material en las construcciones arquitectónicas. Mientras que concedía prioridad a la primera, identificada como la expresión física de un proceso coherente, concebido y realizado por sus artífices originales, la segunda era entendida como el producto de factores eventuales, en cierta medida extraños a la esencia de la arquitectura ${ }^{10}$. En cualquier caso, aunque defendamos la intervención de Valadier en el Arco de Tito, podría parecer que no queda más remedio que aprobar, no obstante con satisfacción, la práctica de restaurar una obra arquitectónica o un fragmento de ella, a través de la reproducción de la idea que se tiene de la misma.

8 Vid. la elaboración del Manual de Recuperación que inicia su actividad en la segunda mitad de los años 80 con la primera edición del Manual del Comune de Roma, editado en 1.989 en la Tipografía del Genio Civil (DEI).

${ }^{9}$ LA REGINA, F.: Come un ferro rovente, Napoli, 1.992

${ }^{10}$ LEMAIRE, R.: “Autenticitá e Patrimonio Monumentali”, Restauro n. 129, Napoli, 1.993. 


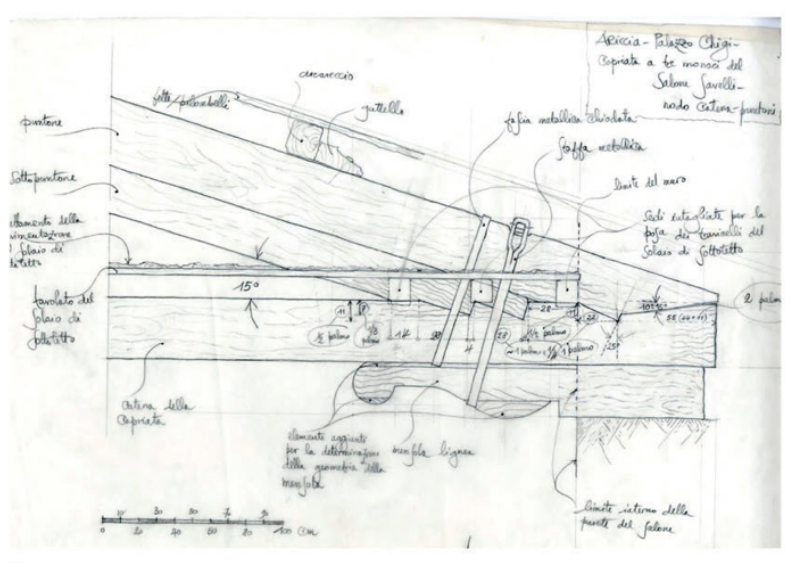

A

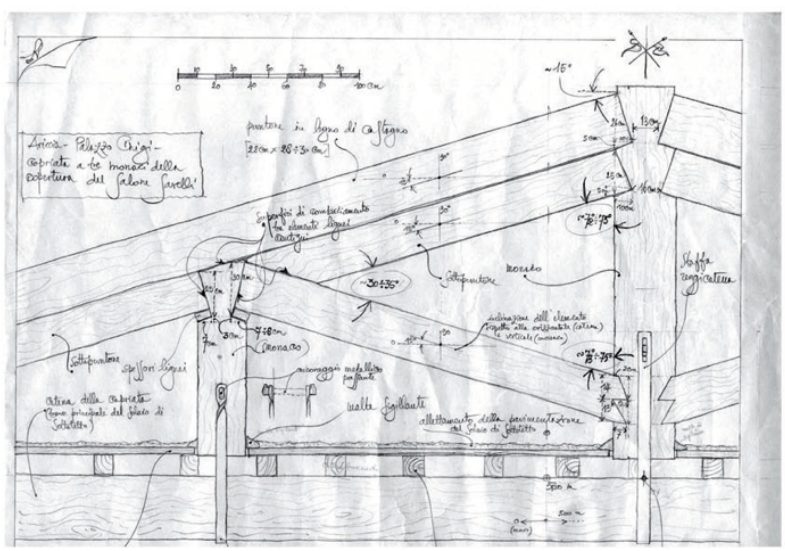

B
Fig.2. Fuentes directas para la historia de las técnicas constructivas tradiciona- les. (A). El levantamiento de tipo arqueológico antecede a las intervenciones de la restauración filológica de las cerchas típicas del 1500, en el Palacio Chigi de Ariccia (Roma). Composición del nodo del tirante con los pares. PUGLIANO, A.: Taccuino di Cantiere, 1995

(B) Composición en la unión entre el pendolón, techo falso y pares. PUGLIA- NO, A.: Taccuino... (op. cit).

Ciertamente, una idea que sea realmente conocida y fundamentada, fruto de un proceso crítico de estudio y de verificación de las fuentes, resulta útil para definir una forma de arquitectura que debe ser dotada de significado o valor, similar a la autenticidad de la materia. Una vez identificadas las peculiaridades de la restauración desde la óptica que considera la atribución de valor a la materia arquitectónica auténtica, la actividad restauradora debe afrontar nuevos riesgos. El mayor de el los se plantea desde la operatividad del restauro, pues si ésta se fundamenta en un vínculo de tipo mimético, se inclinará a producir un elemento simulado, más que a estimular su sentido mediante la imitación. La relación entre la preexistencia de los fragmentos y su restauración, en el primer caso, atiende sólo a la fisonomía del elemento y se basa generalmente, en el uso y reutilización de un material, que resulta útil al restaurador para no evidenciar sus limitaciones comprensivas sobre las potencialidades del léxico constructivo al que se enfrenta.

Un ejemplo representativo lo constituye la sustitución de las cerchas, que a pesar de ser replanteadas en madera, y en el mejor de los casos, se recurra a una geometría análoga a la preexistente, no resulta extraño que sean sistemáticamente privadas de las técnicas de unión entre las partes, expresión de la cultura técnica precedente. De este modo, se realizan estructuras que prescinden de la complicada jerarquía de las articulaciones y sabias entalladuras relacionadas con la disposición local de las fibras de la madera, las cuales son ensambladas con un sistema de clavos apropiados, para mantener en su lugar cada uno de los componentes de la madera unidos simplemente por sus extremidades. Estas estructuras de sustitución no permitirán conocer la intervención del artífice primitivo, perdiendo completamente su valor histórico, como testimonio de los hábitos constructivos pertenecientes a un período, lugar y autor determinados. Podemos observar aún, que el 

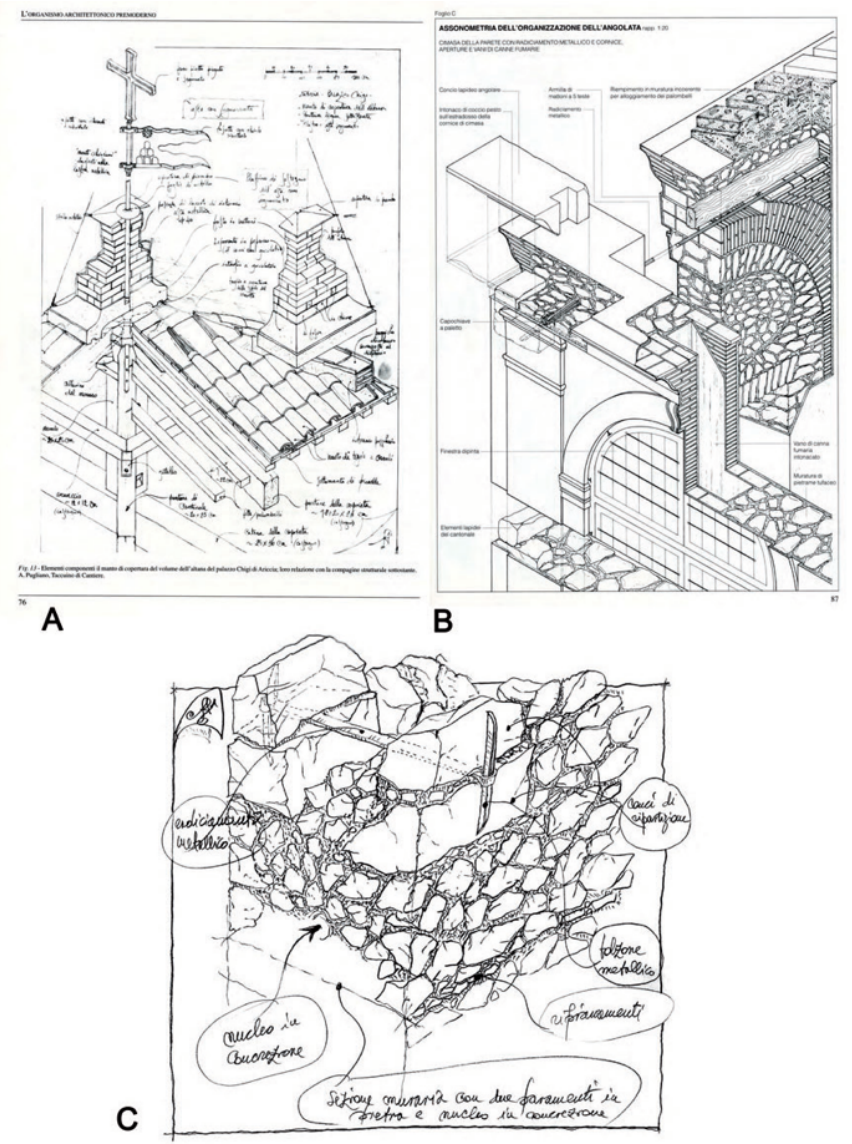

Fig.3. Documentación y restauración de los organismos arquitectónicos y sus componentes.

(A)Composición de la cubierta y la estructura en madera con techo en ladrillo del belvedere en el Berniniano Palacio Chigi de Ariccia ( Roma). De: PUG- LIANO, A.: "L'organismo architettonico premoderno" AAVV.: Manuale del Recupero del Comune di Roma, Roma, II Edición ampliada, DEI, 1995, p. 76.

(B)Ibídem. La composición del muro del belvedere en el Berniniano. Palacio Chigi de Ariccia (Roma). PUGLIANO, A.: 'L'organismo... (op. cit.) p. 87.

(C)Documentación de las Reglas del Arte tradicional antisísmica. Descrip- ción del sistema de unión entre los parámetros del muro en piedra rústica, usado en el Aquila durante las construcciones sucesivas al terremoto del 1703. MiBACComitato Rischio Sismico e Università di Roma "La Sapienza": Studio delle Tecniche Premoderne di Prevenzione Sismica in Lazio, Umbria Abruzzo e Irpinia. PUGLIANO, A.: Indagini preliminari allo svolgimento della ricerea Frafici dei Snnrallunohi

panorama cultural del período ha aprovechado los importantes estudios sobre la historia de la construcción, utilizándola con el fin de recomponer y sistematizar, si bien con fines aplicativos, los aspectos teóricos relativos a la práctica constructiva tradicional ${ }^{11}$. En concreto, todas estas cuestiones han sido útiles para implementar los conocimientos de tipo científico, pues han generado una mayor comprensión de los restauradores, contribuyendo a entender mejor las particularidades de la arquitectura histórica y a desligarse de las elecciones arbitrarias de tipo empirista. Las fuentes para efectuar esta clase de investigación son de tipo bibliográfico, documental archivístico y gráfico, y las informaciones extraídas de estas fuentes son verificadas a través del análisis y de la sucesiva demostración a través de ejemplos reales seleccionados [fig. $2 \mathrm{a}, 2 \mathrm{~b}$ ].

\section{E1 Proyecto de restauración como "Instrumento de Conocimiento"}

Gracias al uso de tales instrumentos culturales, el proyecto de restauración ha adquirido habitualmente el cariz de un proyecto del conocimiento, puesto que el conocimiento, en el campo de la restauración, se alcanza por medio del proyecto en sí. De hecho, en el momento en el que se proyecta la restauración, resulta necesario estar predispuesto a conocer, elaborar y desarrollar rigurosamente los aspectos técnicos y científicos de la arquitectura, con una

11 Fundamentos de la tradición constituyen los textos de: BENVENUTO, Edoardo: La scienza delle Costruqioni nel suo sviluppo storico, Florencia, Sansoni, 1.981 y DI PASQUALE, Salvatore: l'Arte del Costruire.-Tra conoscenza e scienza, Venecia, Marsilio, 1.996. A partir de estos pueden agregarse títulos de disposiciones eminentemente didácticas que permiten éxitos fundamentales, como GIUFFRE, Antonino: La meccanica delle murature storiche,Roma, 1.990; hasta llegar al reci- ente GALLO CURCIO, Antonino: Sul consolidamento degli edifici storici, Roma, EPC Libri, 2.007. 
perspectiva que traduzca los aportes interdisciplinares de los historiadores, de los especialistas en estructuras, de los proyectistas de tecnologías..., en una experiencia interdisciplinar, como conocedores de la arquitectura. El patrimonio arquitectónico europeo, particular-mente el italiano, está conformado en su gran mayoría por edificios con estructuras tradicionales construidas durante diferentes siglos, producto de una admirable actividad humana. El mantenimiento de este patrimonio depende de la capacidad de las instituciones y de los restauradores para proceder oportunamente, aplicando las metodologías de análisis y las técnicas de intervención más idóneas.

En esta línea de reflexión, la disciplina de la restauración arquitectónica ha pasado por una delicada etapa de reflexión, que ha sometido a discusión el convencimiento ilimitado sobre el uso predominante de materiales y técnicas contemporáneas usadas en las nuevas edificaciones. Por ello, la atención de los técnicos se ha dirigido a aunar el necesario conocimiento de las arquitecturas tradicionales, con la voluntad de intervención sobre éstas de una manera adecuada, a través del uso de técnicas y materiales realmente compatibles por su idoneidad filológica y mecánica, y sustancialmente, afines con el contexto preexistente por su comportamiento y durabilidad. Recapitulando, ahora más que nunca existe la convicción de que conciliar los aspectos relacionados con la "ideación” y la "realización" arquitectónic, es una necesidad.

El estudio de la arquitectura revela cómo la mutación histórica de las técnicas constructivas y la conciencia científica se reflejan de una manera puntual en las construcciones. Por otra parte, descubre que la cultura técnica y cientifica que informa sobre la historia de las ciudades, permanece en el ánimo de sus artífices permanentemente ligada con las otras manifestaciones culturales. Con el acontecer del tiempo, el espacio cambia y va adquiriendo las connotaciones particulares del ámbito local que caracterizan la forma de vivir de los pueblos. Intervenir los monumentos mediante restauración exige identificarse con aquella cultura, comprender su discurso y reanudarlo en los términos más adecuados, para completarlo y conducirlo a las conclusiones que hoy se necesitan ${ }^{12}$ [figs. 3a, 3b]. Por lo tanto, la misma teoría de Cesare Brandi, en su definición de restauración, introduce la necesidad de una praxis completa y coherente, ligada a un contexto científico que conduzca medi- ante el conocimiento profundo del objeto, a la formulación de un juicio sobre aquél. Por otra parte, además de las sucesivas consideraciones del valor como requisito enormemente didáctico para nuestros fines, Brandi circunscribe el ámbito que ex- plica la intervención de restauración: no se trata de la imagen de la arquitectura, pero sí de su esencia material. Esta última es el producto de la experiencia de los maestros del oficio y de sus artífices, que dentro de los organismos arquitectónicos, no consideran la distinción entre los componentes puramente formales, y la labor constructiva y estructural necesaria para realizarlos. Se trata de una experiencia cimentada durante siglos y perfeccionada paulatinamente según las pautas de un código, que constituye la regla del arte. Desde este punto de vista se encuentra la justificación, tanto del orden arquitectónico, con su partición métrica y las impli- caciones estilísticas, como también, de la tipología de los elementos estructurales conectados a los conceptos mecánicos contemporáneos, que se muestran a través de la selección de la tecnología más conveniente. En virtud de lo cual, el conocimiento de las características de la arquitectura constituye la única fuente para obtener una percepción correcta y la concreción de todas las iniciativas encaminadas a su conservación, así como de sus valores intrínsecos, entre ellos el valor histórico, expresado en la lógica constructiva. Desde este punto de vista, la documentación de la técnica constructiva vigente se configura esencial, ya que determina el nivel de comprensión de los aspectos técnicos, concebidos en la fase de creación y desarrollados durante la ejecución de la obra. En esta clave de lectura, la investigación histórica contribuye a la organización de instrumentos operativos de tipo bibliográfico, documental, archivístico e iconográfico, que han sido investigados, hasta hoy en día, en

${ }^{12}$ Cfr. GIUfFRÉ, A.: Monumenti e terremoti- problemi statici del Restauro, Roma Multigrafica editorial, 
profundidad y de forma continuada, aglutinando una notable serie de aportaciones científicas ${ }^{13}$.

En otro orden de cosas, entre las fuentes gráficas para la historia consideradas y analizadas, la literatura científica reviste un papel fundamental. Por una parte, la tratadística y la manualística de la arquitectura, entre otras, desarrolladas particu- larmente en los siglos XVIII y XIX, clarifica los criterios y peculiaridades para una mejor ejecución de las obras, sin dejar de lado la información científica vigente; mientras que por otra parte, las normas de la construcción pre-moderna, especialmente de tipo antisísmico, analizan mediante recomendaciones, los parámetros de eficacia y seguridad a seguir en las construcciones. ${ }^{14} \mathrm{La}$ documentación existente en los archivos que atañe a la contabilidad de las construcciones, así como a los contratos con los operarios, informa sobre las soluciones particulares adoptadas en cada una de las construcciones, y en el caso de las memorias de los técnicos, revela el criterio adoptado en su análisis de la seguridad de la construcción, relacionando el conocimiento mecánico y los puntos débiles registrados.

La información obtenida es producto de los mencionados instrumentos historiográficos y se encuentra acreditada, perfeccionada y profundizada mediante la interpretación de los materiales objeto de la restauración. En esta ocasión, la operación del levantamiento, la deducción geométrica y las dimensiones arquitectónicas deben estar integradas por observaciones tecnológicas, tendentes a describir cualitativamente los aspectos estructurales y constructivos a través de la elaboación de planos de detalle [fig. 3c]. Por otra parte, la documentación sobre el estado de conservación también manifiesta la debilidad estructural: por acción natural, por factores externos traumáticos o bien por transformaciones propias del transcurrir del tiempo. La posibilidad de emitir un juicio sobre la eficacia de las técnicas empleadas por los antiguos artífices, está orientada a completar el conocimiento y favorecer la existencia de un panorama científico eficaz para definir los parámetros idóneos en las valorizaciones.

Una contribución fundamental a la formación de este panorama científico tiene su origen en los inicios de los años ochenta del siglo XX, a partir de los estudios surgidos sobre el comportamiento de las estructuras antiguas con muros de carga. Si atendemos a investigaciones que tratan el tema sísmico y parten de la revisión de los materiales utilizados en estructuras antiguas, se considera la posibilidad de agrupar dichas estructuras en tipologías, para documentar su grado de adhesión alos criterios constructivos reconocidos por las reglas del arte. Posteriormente, se seguirá con la definición de la modalidad de desplome a la que pueden estar expuestos los modelos correspondientes a dicha tipología, a causa de sus características morfológicas [figs. 4a, 4b]. Se trata de identificar los mecanismos de los posibles daños originados por acciones externas, así como de la definición del papel que desempeñan todos los elementos que conforman una sección del muro presentes en cantidad y distribución, de tal forma que contribuyan a posibilitar un comportamiento mecánico eficaz en dicho muro. Las fábricas arquitectónicas son descritas a través de levantamientos de carácter arqueológico, acompañados generalmente de fichas con recopilación de textos que complementan el conocimiento de las características propias de la construcción tradicional de cada lugar. Los datos conocidos y citados anteriormente se utilizan con el fin de obtener

13 Se acude para esto a las actuales orientaciones de los estudios y de la producción científica de algunos investigadores activos en el contexto de la Biblioteca Hertziana, con la difusión On line de un glosario por argumentos de términos arqui- tectónicos y constructivos y la publicación de monografías sobre temas de la práctica y de la ciencia ligada a la construcción.Cfr. SCHLIMME, Hermann: Practice and Science in Early Modern Italian Builiding. Towards and Epistemic History of archirecture, Roma-Bari, Electa, 2.006

14 e acude al rico repertorio documental de las Relaciones técnicas que miran hacia el futuro respecto a las catástrofes o los reglamentos de construcción encaminados a la reconstrucción. En relación a esto último vale la pena recordar il "Regolamen- to della cittá di Norcia" redactado en 1.860 por Luigi Poletti y por Angelo Secchi, o la norma indicada por Messina en 1.909 en el contexto del trabajo de la Comisión dirigida por Antonio Reycend. 
A

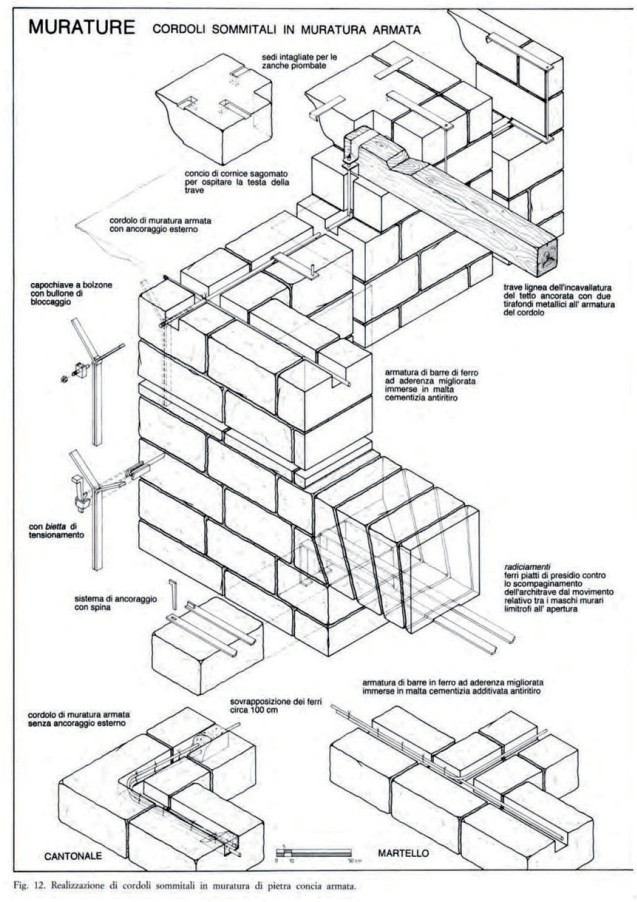

B

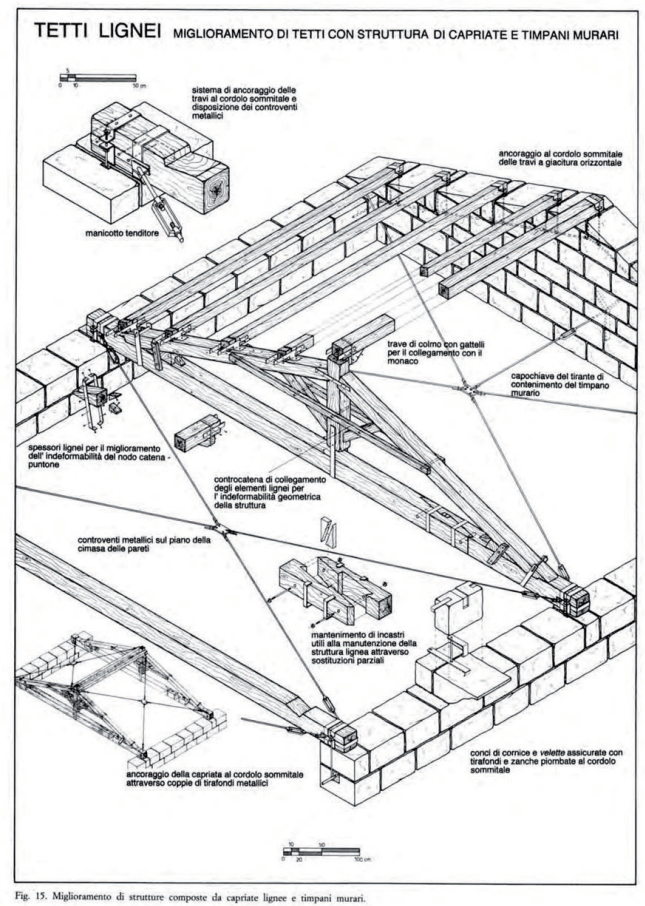

Fig.4. Definición de los criterios de intervención filológica para la restauración y prevención sísmica en la edilicia tradicional de Palermo.

(A) Intervenciones sobre los muros. PUGLIANO, A.: "Criteri per il restauro strutturale e antisismico nell'edilizia storica" AAVV.: Manuale del Recupero del Municipio di Palermo, Palermo, Flaccovio, 1997, p. 303.

(B) Intervenciones sobre las estructuras de la cubierta en madera. DITSITA NTO A " $r$ ritari (nn rit) n 207

el reconocimiento científico de la Regla del Arte tradicional y de la identificación de las condiciones de riesgo sísmico, derivados del proceso formativo de la obra. Esta última se relaciona con aquellos sucesos que son consecuencia de la organización arquitectónica (a nivel formal y material) que se generan en las construcciones, determinadas por transcurso histórico particular, pero que se aplican a un escenario global de composiciones y construcciones tradicionales con importancia antropológica.

La primera síntesis metodológica que conjuga las prácticas constructivas par- ticulares y las costumbres tipológicas de la arquitectura, caso por caso y en clave procedimental, para valorar la vulnerabilidad sísmica de los asentamientos urbanos históricos, se debe a Antonino Giuffré. El estudio y la propuesta del grupo de investigación dirigido por Giuffré hasta fines del siglo XX, estaban encaminados a comprender la fisiología de la arquitectura tradicional en sus conformaciones locales. Su objetivo era analizar el grado de riesgo sísmico derivado de los peligros más o menos evidentes, intrínsecos al proceso formativo y trasformativo de las construcciones y de los tejidos. Finalmente, a partir de los datos extraídos fue posible conocer las intervenciones delimitadas y señaladas, de tal forma que fueran eficaces y apropiadas a nivel mecánico y filológico. ${ }^{15}$ La potencialidad operativa de esta metodología no

15 Para una mejor comprensión de esta relación debemos recurrir a la copiosa producción del Codici di Pratica, a partir de GIUFFRÉ A., (a cura), CERADINI, V., JACOVONI, F., PUGLIANO, A.,ZAMPILLI, M.: "Centri storici in zona sismica. Analisi della danneggiabilitá e teniche di intervento conservativo. Castelvetere sul Calore", en: Studi e ricerche sulla si- curezza sismica dei monumenti,n. 8, Roma, Departamento de Ingeniería estructural y geotecnica Universidad “La Sapienza”, noviembre 1.988. 

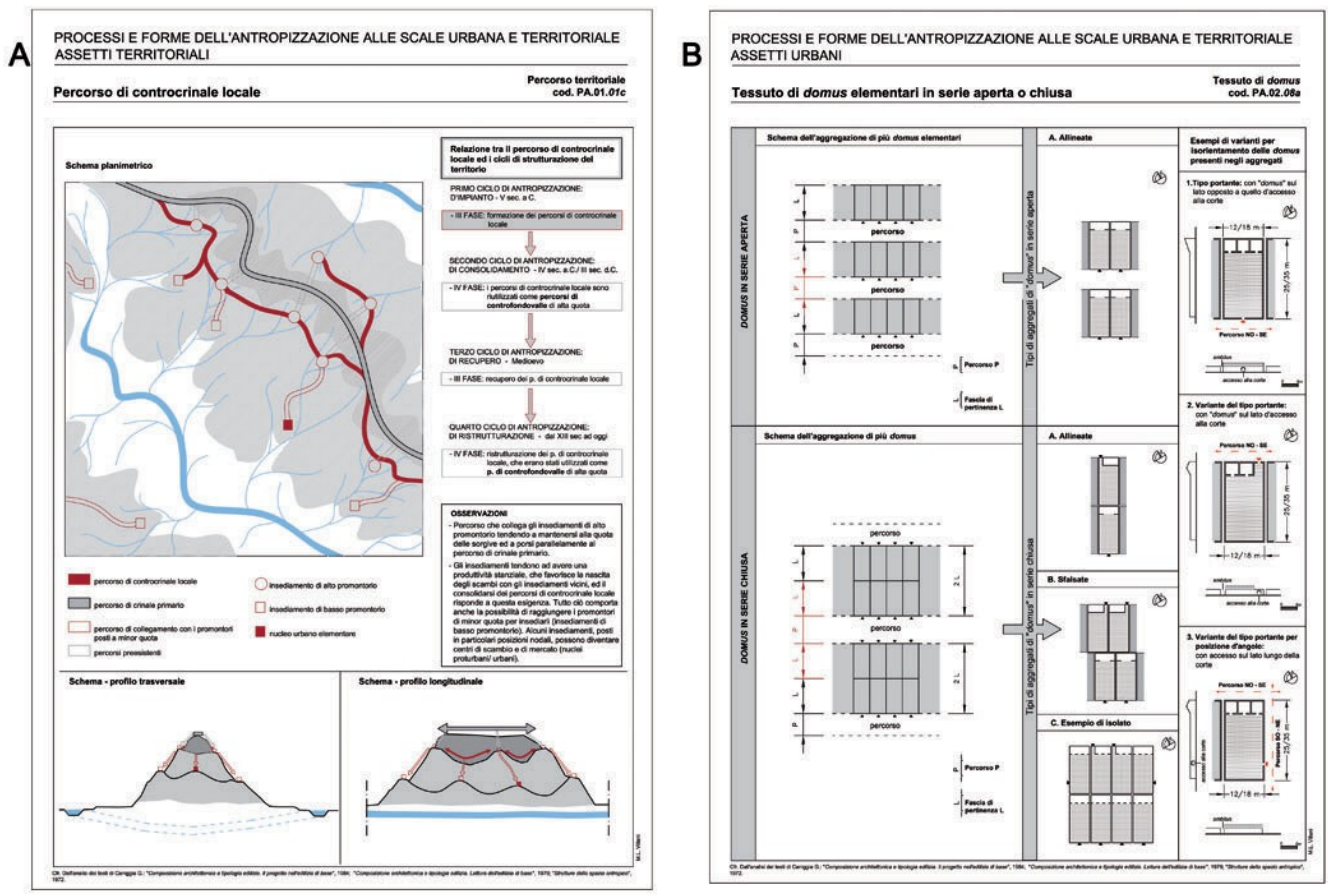

Fig.5. Evolución de los instrumentos para el reconocimiento del valor y para la restauración filológica de la arquitectura, de los lugares y del paisaje.

(A)Descripción de los modos históricos de antropización y uso del territorio. Recorridos del territorio dispuestos en la pendiente de la falda de la montaña y asentamientos en la parte alta del promotorio. [Fich a gráfica cod. PA.01.01c

7. PUGLIANO, A.: Elementi di un Costituendo Thesaurus utile alla conoscen- za, alla tutela, alla conservazione dell'architettura, Roma, 2 vol., Prospettive, 2009.

(B)Descripción de las antiguas disposiciones de los tejido urbanos de las Do-mus elementales. [Ficha gráfica cod. PA. 02. 08a]. PUGLIANO, A.: Elementi di...(op. cit).

pasó inadvertida y el mismo Servicio Sísmico Nacional decidió proveerse de un Atlas de los Centros Históricos Italianos expuestos al riesgo sísmico, que, asentado en una Base de Datos, reuniera de forma sistemática un cuadro informativo enfocado al método en cuestión. ${ }^{16} \mathrm{El}$ éxito de dicho criterio, en términos de operatividad, fue importante y se estima duradero; el papel fundamental de la filología, que evidencia la importancia del proyecto, ha fortalecido la función y finalidad de los análisis de carácter histórico, así como de las investigaciones sobre el soporte vivo de las construcciones. Las decisiones sobre el proyecto se pueden evaluar en términos de calidad, según criterios de argumentación y rigor científico, mientras que en lo concerniente a su realización, una vez planteado definitivamente el concepto de minima intervención, se reconoce la primacía del continuo manten- imiento, sobre la esporádica restauración. De este modo, prima el equilibrio y el orden también en el ámbito de la intervención estructural. Por lo tanto, las herrmientas idóneas para el ejercicio del método son: instrumentos culturales destinados a aplicarse en el contexto de actividades de reconocimiento, documentación y proyección de la restauración.

16 Para profundizar sobre las indicaciones del Servicio Sísmico Nacional, véase PUGLIANO, A.:"La prevenzione sismica alla scala territoriale." "L'Atlante dei Centri storici Italiani esposti al Rischio Sismico" en: Ricerche di Storia dell'Arte, n. 65 N.I.S., Roma, 1.988. 


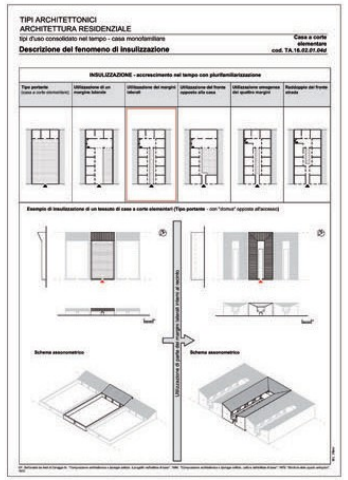

A

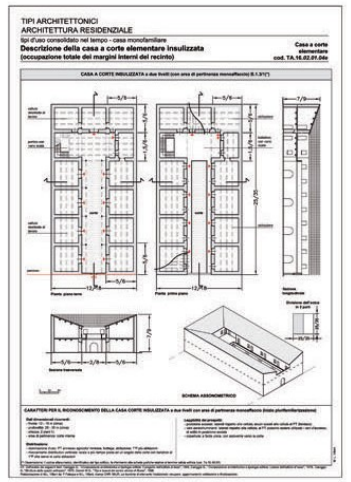

B

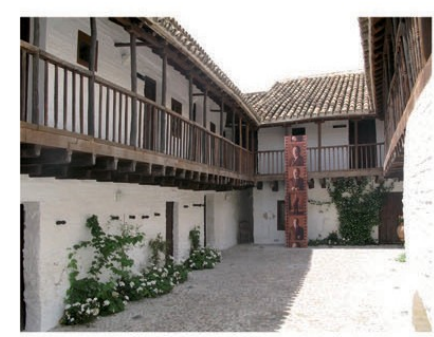

c

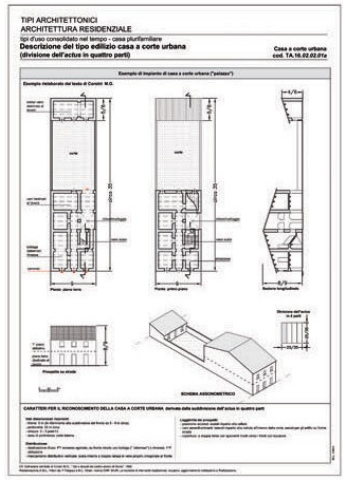

Fig.6. Evolución de los instrumentos para el reconocimiento del valor y para la restauración filológica de la arquitectura, de los lugares y del paisaje. Descripción de los procesos que regulan el crecimiento de la arquitectura tradicional y la transformación de los tipos constructivos.

(A) Proceso de « insulización » u ocupación progresiva mediante nuevos volúmenes de habitación : el recinto residencial se vuelve multifamiliar. [Fi- cha gráfica cod TA.16.02.01.04d]. PUGLIANO, A.: Elementi di...(op. cit).

(B) Ibídem. La ocupación completa del recinto residencial genera un tipo constructivo específico, todavía reconocible en los tejidos edificados medi- terráneos. El dibujo describe dicho tipo multifamiliar, que crece en extensión. [Ficha gráfica TA.16.02.01.04e]. PUGLIANO, A.: Elementi di...(op.cit).

(C) La Posada del Potro (Córdoba, España, s. XVI) puede ser sin duda, recon- ocida como un ejemplo de casa de patio convertida en una ínsula. Tal recon- ocimiento sugiere nuevas e interesantes perspectivas de estudio acerca de la matriz cultural y antropológica de la arquitectura histórica urbana, y sobre los modos tradicionales de su desarrollo hasta tiempos recientes. Foto: Antonio Pugliano (2011). Agradezco al Profesor Fernando Moreno Cuadro su preciada guía en la interesante visita realizada por la ciudad de Córdoba.

(D) Evolución de los instrumentos... (cit. fig. 6). El tipo edilicio de la casa de patio urbana, originariamente construida en extensión, es caracteristico de Roma moderna. Éste testimonia el efecto, desde la antiguedad, de una fuerte tendencia por parte de los propietarios, al aumento de la densidad de habitación. El tipo tiene su origen en la división del lote originario del suelo, antes de su completa ocupación.

\section{Más allá de los Manuales de Recuperación El Thesaurus de Arquitectura}

El siglo XXI, registra una importante evolución en la práctica de la documentación de la Arquitectura de interés histórico, artístico y antropológico, hasta ahora desarrollada a través de la publicación de los Manuales de Recuperación. La Catalogación de los bienes culturales arquitectónicos vuelve a asumir un papel importante en la producción de instrumentos culturales, indispensables para un conocimiento más profundo de la arquitectura histórica, así como de los procesos de evolución y agregación en sus contextos territoriales.

El escenario operativo actual, de hecho, está fuertemente influenciado por el Thesaurus de Arquitectura instaurado concebido desde el Istituto Centrale per il Catalogo e la Documentazione del Ministero dei Beni Culturali (ICCD) y la Uni- versidad "Roma Tre". ${ }^{17}$

17 Observese la investigación inherente al Thesaurus de Arquitectura que fue elaborada en el contexto de la Convenzione Quadro per l'istituzione e lo svolgimento di attività didattiche e di ricerca sinergiche tra Università "Roma Tre" DiPSA e ICCD. Responsables científicos: por el ICCD el Director Arch.Maria Rosaria Sanzi di Mino; por el DIPSA Paolo Marconi y Antonio Pugliano. La investigación se aplica a la formación de un léxico 
Dicho Thesaurus ha definido con textos y gráficos, los términos de un léxico unificado para su utilización en el desarrollo de las iniciativas de tutela de los bienes arquitectónicos establecidos en el territorio nacional. El Thesaurus de Arquitectura, constituye un testimonio factible para superar la mera demostración de las series agregadas de ejemplos reales descritos en Los Manuales de Recuperación, produciendo un compendio riguroso y orgánico de los usos que caracterizan la existencia de elementos y procesos típicos de la cultura constructi- va tradicional. Desde la documentación de objetos reales considerados ejemplares, se pasa a la descripción del proceso que ha determinado su formación, así como al aspecto tipológico que éstos han asumido: los datos materiales son puestos en relación con las ideas que de ellos se han asimilado. El Thesaurus consiste en un vocabulario abierto; en él, las síntesis tipológicas que se proponen son temporales, susceptibles de ser revisadas y actualizadas, profundizando en aspectos dirigidos a la definición particularizada de los tipos de edificación constructivos y los componentes materiales, ambos correspondientes a ámbitos culturales y geográficos siempre más restringidos.

Llegados a este punto es útil indicar, de manera sintética, la estructura y el contenido del Thesaurus, además de su vocación en el campo de la tutela de los bienes arquitectónicos culturales. La iniciativa del ICCD consiste en establecer un sistema, tendencialmente unitario, de organización y gestión de la información inherente a la arquitectura de interés histórico, artístico y antropológico. Posteriormente se hace activo, produciendo un repertorio de datos o "puntos de referencia", relativos a la catalogación de ejemplos reales una vez reconocidos como pertenecientes a particulares categorías tipológicas. La descripción técnica y procedimental de los datos o "puntos de referencia", constituye un modelo de comportamiento al cual referirse en la fase sucesiva de implementación, mejoramiento y verificación del sistema. El sistema puesto a punto por el ICCD, señala en fase de funcionamiento el papel fundamental de los órganos externos del Ministerio: las Superintendencias locales, que procederán a implementar la recopilación del repertorio tipológico y el mencionado reconocimiento de los casos o ejemplos reales para ser catalogados. La estructura del Thesaurus está organizada jerárquicamente según un sistema de códigos alfanuméricos, basados en la recolección de una serie de descriptores, que definen la tipología de pertenencia y las particulares calificaciones funcionales del argumento del objeto tratado. Junto a estos descriptores de texto se encuentran, en caso necesario, los descriptores gráficos, que toman los esquemas tipológicos y los definen formalmente a través de un diseño producido ad hoc. Los capítulos del Thesaurus, por ahora, reúnen los argumentos relacionados con los principales procesos y formas del antropocentrismo en las escalas urbanas y territoriales, los más difundidos tipos arquitectónicos residenciales y los más tradicionales componentes arquitectónicos y estructurales. De esta forma, son indicados y descritos los ordenamientos territoriales [fig. 5a] y los ordenamientos urbanos [fig. 5b], con indicaciones de los procesos evolutivos particulares [fig. $6 \mathrm{a}, 6 \mathrm{~b}, 6 \mathrm{c}$ y $6 \mathrm{~d}]$.

En lo que respecta a la tipología constructiva edilicia, se consideran los tipos de la antigüedad estimados como eminentemente de sustrato [fig. 7a,7b,7c y7d] y los tipos, que aunque siendo de origen antiguo, su uso se consolida en el tiempo. Por otra parte, la descripción de la tipología residencial prosigue con los tipos de la modernidad y de la contemporaneidad, concluyendo con el retroceso a la casuística tipológica derivada de las experiencias constructivas económicas y populares en Italia, durante el período comprendido entre las dos guerras mundiales. En referencia a las discusiones sostenidas sobre los componentes arquitectónicos y los sistemas estructurales, se han descrito los temas de las estructuras de las

unificado destinado a ser aplicado por los organ- ismos externos de Ministerio, desplegándose la actividad documental de los bienes arquitectónicos diseminados por el terri- torio nacional. A esta actividad le sigue la elaboración de sucesivos convenciones (responsable científico: Antonio Pugliano) entre el DIPSA y el ICCD, correspondiente a la publicación del trabajo ejecutado y la continuación del estudio encaminado a la investigación y aún ahora en curso, sobre la tipología de la arquitectura religiosa. Para la publicación del Thesaurus de Arquitectura se observa: PUGLIANO, A.: Il Riconoscimento, la Documentazione, Il Catalogo dei Beni Archittetonici. Elementi di un Costituendo Thesaurus utile a la conscenza, alla tutela alla conservazione del"Archittetura, 2 voll. Roma Prospettive, 2.009 

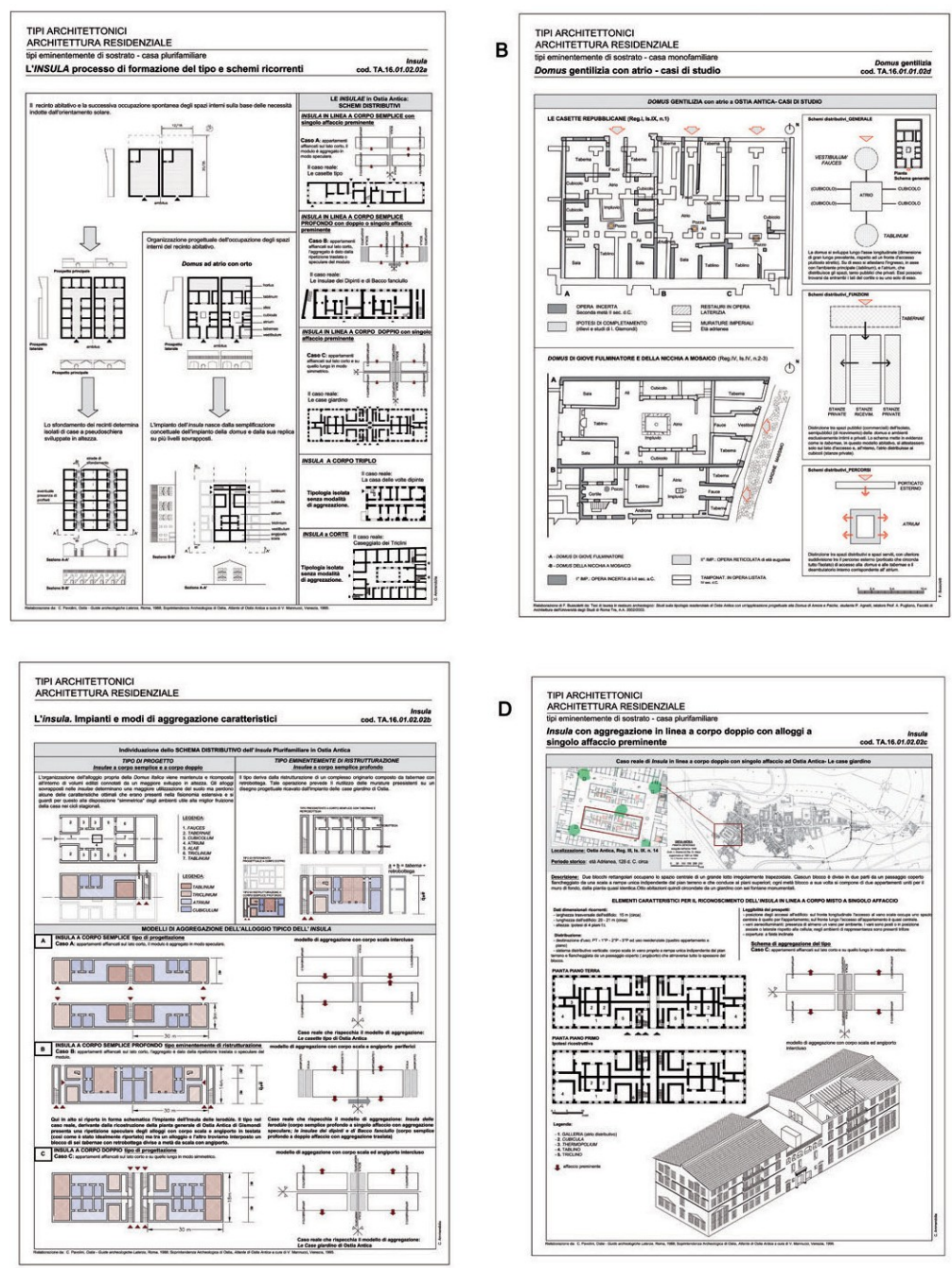

Fig.7. Evolución de los instrumentos para el reconocimiento del valor y para la restauración filológica de la arquitectura, de los lugares y del paisaje.

(A)Procesos que regulan el crecimiento de la arquitectura tradicional y la transformación de los tipos constructivos. Paso de la arquitectura edificada en extensión (de matriz rural), a la edilicia construida en altura (de tipo urbano), en la antiguedad romana determinaba el tipo de la ínsula.[Ficha gráfica cod TA.16.01.02.02a] PUGLIANO, A.: Elementi di...(op. cit).

(B)Documentación de ejemplos reales. Casas en hilera arcaicas y sucesivas domus gentilicias reconocibles en el tejido edificado antiguo de Ostia.[ Ficha gráfica cod TA.16.01.01.02d]. PUGLIANO, A.: Elementi di...(op. cit).

(C) Descripción de los esquemas tipológicos recurrentes en la antigua arquitectura en altura de Ostia. La organización de los alojamientos típicos de la ínsula de varias plantas es tomada de la consolidación del modelo típico de la domus. [Ficha gráfica cod. TA.16.01.02.02b]. PUGLIANO, A.: Elementi di... (op. cit).

(D) Documentación de los ejemplos reales se completa con la Restitución de las hipótesis y fragmentos de los organismos arquitectónicos antiguos. De- scripción arquitectónica de las ínsulas " adrianeas » ostienses denominadas también « casas Jardín ». [Ficha gráfica cod. TA.16.01.02.02c]. PUGLIANO, A.: Elementi di...(op. cit).

cimentaciones [fig. 8], de los muros de carga en elevación, [fig. 9], de los sistemas de arcos y de arquitrabes [fig. 10], de las placas y cubiertas [fig.11], hasta las estructuras de refuerzo estructural. En conclusión, el resultado de un sistema de elementos con un léxico convencional compartido, se convierte en un beneficio para la cultura y para la ejecución del proyecto, sobre todo en el ámbito de las actuaciones encaminadas a la tutela del Patrimonio Arquitectónico, y su aplicación a través de sistemas y procedimientos innovadores.

\section{Programar la conservación y la valorización. Las plataformas digitales}

Los argumentos tratados en el Thesaurus de Arquitectura y el método usado en su exposición, muestran una importante potencialidad aplicativa para la tutela de los centros históricos, que se puede ejercer además, a través del ricorso a tecnologie informatizzate di catalogazione e di gestione di dati su base geografica (GIS). La catalogación de los datos relativos a las características procedentes de la arquitectura y de los sitios, en realidad puede permitir importantes aplicaciones, incluso en lo que respecta a la gestión de programas de intervención dirigidos a la restauración y a la recuperación, basados en un lenguaje compartido e inequívoco, permitiendo niveles aceptables de homogeneidad en la formación y en la implementación de los bancos de datos mencionados. Se trata de garantizar la conservación activa de las arquitecturas y de los espacios urbanos de interés histórico, artístico y 
antropológico extendidos en el territorio nacional, respectivamente, a través de la organización de un sistema informático de archivos y de gestión de datos que caracterizan las arquitecturas y los contextos construidos, así como la puesta en marcha de métodos y procedimientos útiles para el proyecto de restauración antisísmica. El desarrollo de un sistema de información acreditada, resulta necesario para constituir un punto de referencia convencional, tanto en la fase de reconocimiento de las características propias de las arquitecturas y de las estructuras urbanas, como en la praxis archivística de dicha información, con probabilidad, de que posteriormente, puedan facilitar eventuales procesos de homogeneización de los diferentes bancos de datos existentes. La actividad esencial para la formación del sistema mencionado puede resumirse en tres fases: la fase inicial, que se refiere a la producción del conocimiento; la siguiente, a la organización del conocimiento, y la fase con la que se concluye afecta al uso del conocimiento.

La fase de producción del conocimiento se basa en la consecución de datos basados en bibliografías, documentos y levantamientos. Las acciones inherentes a esta fase dependen eminentemente del desarrollo de investigaciones históricas y equipos de levantamiento, documentación gráfica y fotográfica. Se procede a la reunión de información acerca de: la historia, cultura, economía y propiedades locales; el estado y las características arquitectónicas, tanto de los monumentos sobresalientes, como del conjunto de lo construido que crea su trama y la reunión de información sobre usos históricos y usos actuales de la totalidad construida y del tejido. Los descriptores a tener en cuenta son pues, de carácter tipológico, y examinan los procesos de formación y transformación de la construcción y de los tejidos en el escenario de sus inclinaciones al uso, aplicándose, técnicamente, a la constitución física individual de los edificios con particular atención en sus componentes arquitectónicas, estructurales, formales y cromáticas.

Para que un trabajo de este tipo produzca resultados eficaces se deben tener en cuenta las condiciones del entorno, relativas a la unión e integración con el repertorio de datos existentes sobre las características del territorio. También es necesario el reconocimiento de estudios sobre el territorio de carácter normativo y técnico (manualística, directrices...) para la restauración y recuperación arquitectónica, y sobre la planificación, tanto a nivel comunal como supra comunal. Asimismo, es indispensable la referencia a la actual producción del Banco de Datos, extrapolable a otros sectores de la Administración Pública a nivel nacional, para poder dirigirse conscientemente a la homogeneidad de la producción de información y a la compatibilidad de la arquitectura del sistema. Por otra parte, hay que atender a Protección Civil (anteriormente, Servicio Sísmico Nacional de la Presidencia del Consejo de Ministros), que utiliza para sus estudios de vulnerabilidad el Atlas de los Centros Históricos Italianos Expuestos al Riesgo Sísmico; también al Ministero per Beni e le Attività Culturali, que bajo las Direcciones Regionales, conserva datos relativos al patrimonio, organizados en algunos casos, mediante soporte digital. Dicho Ministerio, por medio del Istituto Centrale per il Catalogo e la Documentazione, en el contexto del SIGEC, tiende a producir y gestionar en su plataforma digital, lo relativo al archivo y al uso de los datos relacionados con el inventario de sus bienes culturales. En este proceso operativo, entre otras cuestiones, se rastrean de manera minuciosa, interesantes experimentaciones sobre ámbitos temáticos tendentes a profundizar en el ámbito territorial circunscrito. Es el caso del Banco de datos llamado Oikia, se refiere a la documentación de la consistencia de los Bienes Culturales de propiedad pública en el ambiente romano.

La fase sucesiva perteneciente a la organización del conocimiento, consiste en la sistematización de los datos en una base informática. Las acciones correspondientes son: la definición y la codificación de las informaciones con el desarrollo de anexos para cada uno de los datos; formación del Banco de Datos complementada con el Glosario de repertorios, y formación de la base gráfica a la cual referir al Banco de datos. Se trata de identificar, caracterizar y localizar las características arquitectónicas y tipológicas referidas a los materiales, funcionalidad de la edificación y del tejido; identificándose además, la información relativa a los usos históricos y actuales, así como para considerar la "vocación de reutilización": los usos esperados. 
Fig. 8. Evolución de los instrumentos para el reconocimiento del valor y para la restauración filológica de la arquitectura, de los lugares y del paisaje. Descripción de la tipología estructural de los componentes materiales que conforman la arquitectura tradicional. Cimentaciones indirectas y profun- das sobre palos en madera. [Ficha gráfica cod. SS.01.04d]. PUGLIANO, A.: Elementi di...(op. cit).

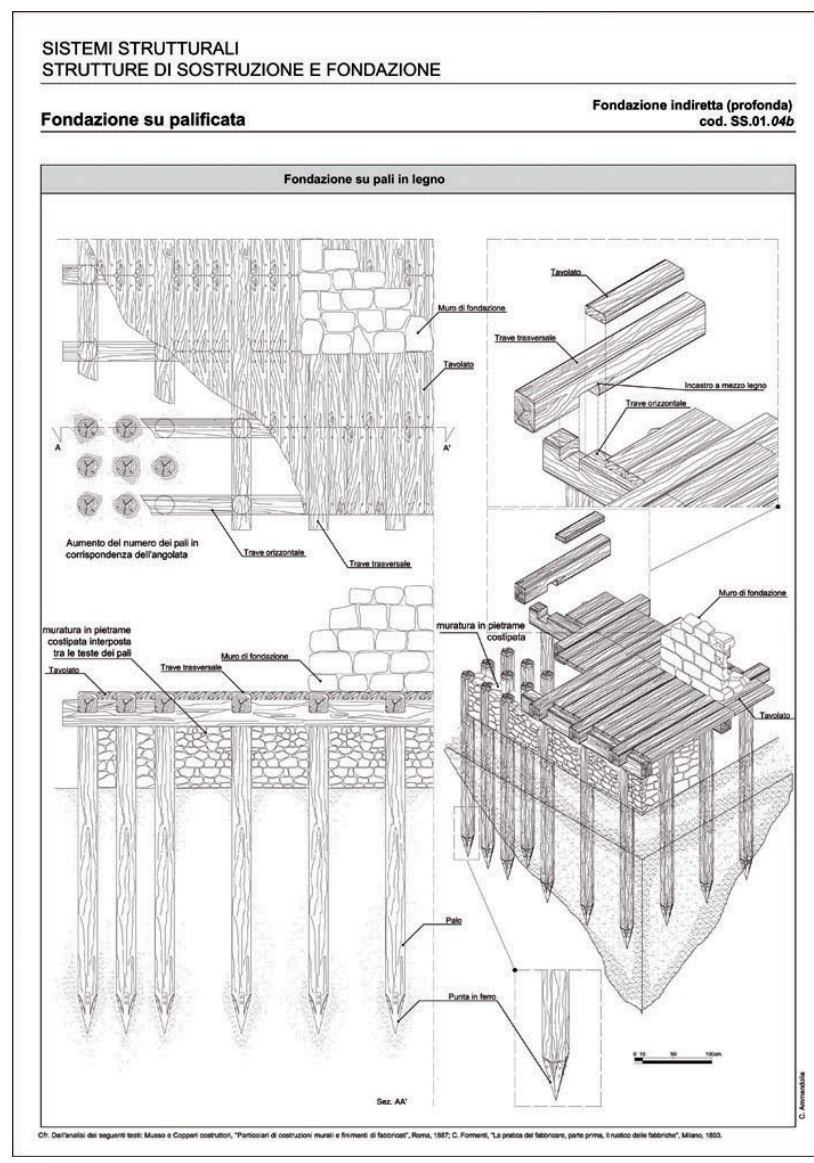

Con el fin de valorizar, en el sentido expuesto en la Ley de Bienes Culturales, resulta necesario identificar, caracterizar y localizar también los elementos materiales e inmateriales y, con éstos, los motores de desarrollo y rentabilidad. La fase conclusiva, pertinente al uso del conocimiento, tiene que ver con la producción de la síntesis de los datos con una finalidad operativa y con una carácter programático y proyectual. La acción relativa a esta fase, se refiere tanto a la producción de la información, como sustento de la actividad de proyección de los técnicos locales y a la óptima gestión de las relaciones entre Administración y Ciudadanos, como a la producción de propuestas para la valorización y el desarrollo económico de determinados ámbitos territoriales y de construcciones particulares y/o recorridos, reconocidos como componentes esenciales de un próximo museo extendido. La información producida tiende a individualizar, localizar y caracterizar la tipología de la intervención de tutela, conservación, recuperación y valorización, la cual va referida en forma detallada, al conjunto edilicio y al tejido urbano. Las informaciones tienen un carácter aplicativo y describen, desde el punto de vista técnico, normativo, procedimental, administrativo y estimativo, los tipos de intervención de tener en cuenta para proyectar y programar. Estas informaciones deben ser accesibles al público de manera virtual, componiendo o completando el cuadro documental y las ofertas de servicios de la Administración Pública. El tema de la valorización está desarrollado en el plano programático, a través de la identificación, la caracterización y la localización de los espacios que esperan ser usados, tema que está relacionado con el sistema de la arquitectura para la receptividad y la musealización. Tanto para uno como para otro, está indicado el modo apropiado de reutilización y el repertorio de informaciones técnicas, útiles en la fase de su realización. 


\section{Un ejemplo para concluir: El programa para la tutela, la conservación y la valorización del sitio arqueológico de Ostia ${ }^{18}$}

Para concluir, expondremos una aplicación del método descrito anteriormente. Se trata del desarrollo de un programa de búsqueda, que tiende a reunir a su alrededor un tema de trabajo coordinado por Instituciones Científicas de Tutela de los Bienes Culturales Arquitectónicos y Arqueológicos, con el fin de que cada una, por su propia especificación y competencia, pueda formar una sinergia científica, operativa y didáctica.

El programa de búsqueda está elaborado para constituir un sistema para la documentación, la conservación, la valorización, la gestión y para salvaguardar el contexto ambiental (natural y del hombre) del sitio arqueológico de la Antigua Ostia. Dicho programa desarrolla el tema de la valorización, inclusive con fines turísticos, y por lo tanto, de una gestión eficaz de posibles atractivos materiales e inmateriales. El programa, que se ocupa de la identidad de los caracteres permanentes de a cultura antigua, está orientado hacia el conocimiento de los procesos formativos y transformativos del conjunto urbano y de sus construcciones. Esto último, por tanto, antes que ser expresión material de las costumbres y de las relaciones ambientales con significado cultural y antropológico, representa un lugar concreto donde localizar y desarrollar las intervenciones propuestas. El fin de tal estudio es la proyección de una eficaz actividad de tutela (conocimiento, documentación y restauración), a través del reconocimiento del valor histórico, artístico y antro pológico, además de los significados culturales y arquitectónicos que inciden en el patrimonio arqueológico. Ello contribuye a la supervivencia del conjunto material exaltando las dotes de expresividad y la inclinación hacia su utilización, para facilitar el uso didáctico del contexto monumental urbano de la Antigua Ostia por parte de la comunidad.

El programa unifica pues, aspectos cognoscitivos y aspectos que proponen caracteres operativos. El conocimiento del sitio arqueológico estará encaminado a la documentación y caracterización de los atractivos presentes, y las propuestas operativas se basarán en la definición de posibles formas concretas de valorización. Desde esta perspectiva, se llega a la proyección de una nueva cualificación del sitio, en lo que respecta a la escala urbana y a la realización de recorridos culturales temáticos dotados de un ámbito expositivo idóneo. Éstos últimos, así como los recorridos, serán organizados en contextos físicos seleccionados y adecuadamente calificados, reintegrados y con las funciones requeridas para un museo abierto y difundido.

Las propuestas operativas de carácter proyectual, serán descritas con la profundidad necesaria para exponer su real factibilidad desde el punto de vista económico/ gestionable y técnico/constructivo. Las descripciones documentarán el repertorio de los tipos de construcciones, el léxico constructivo local, así como el análisis y el proyecto de las zonas constructivas ejemplares.

Recapitulando se pone en marcha una serie de manuales sobre bases digitales que atenderán al proyecto y al escenario normativo a los cuales se refiere, con-frontando las acciones y los productos: el método para un proceso proyectivo de calidad. Se trata, además, de proceder a la definición y experimentación de un modelo completo de archivos de datos (GIS) con el fin de obtener la óptima aplicación de la metodología puesta en funcionamiento [figs. 12-13].

La divulgación de los datos recopilados y organizados será realizada por la publicación de las Lineas operativas para el proyecto de la valorización y la restauración, en el campo territorial considerado y dicha publicación consistirá en la declaración editorial del GIS. Esta podrá ser

18 La actividad de búsqueda aplicada y de didáctica desarrollada en una convención entre MiBAC y la Universidad de "Roma Tre" DiPSA, tiene por objeto la formación de un "programa para la documentación, la conservación y la valorización del sitio arqueológico de la Antigua Ostia". De dicha Convención son responsables, por el MiBAC, Angelo Pelegrino director de las excavaciones; Marco Merelli, director de la oficina técnica de excavaciones y, cada uno por su propia representación, Marco Sangiorgio, director de cartografía; Giovanna Arciprete, arqueóloga y Laura Spada, conservadora; por la Universidad "Roma Tre" DiPSA, el científico responsable es Antonio Pugliano. 


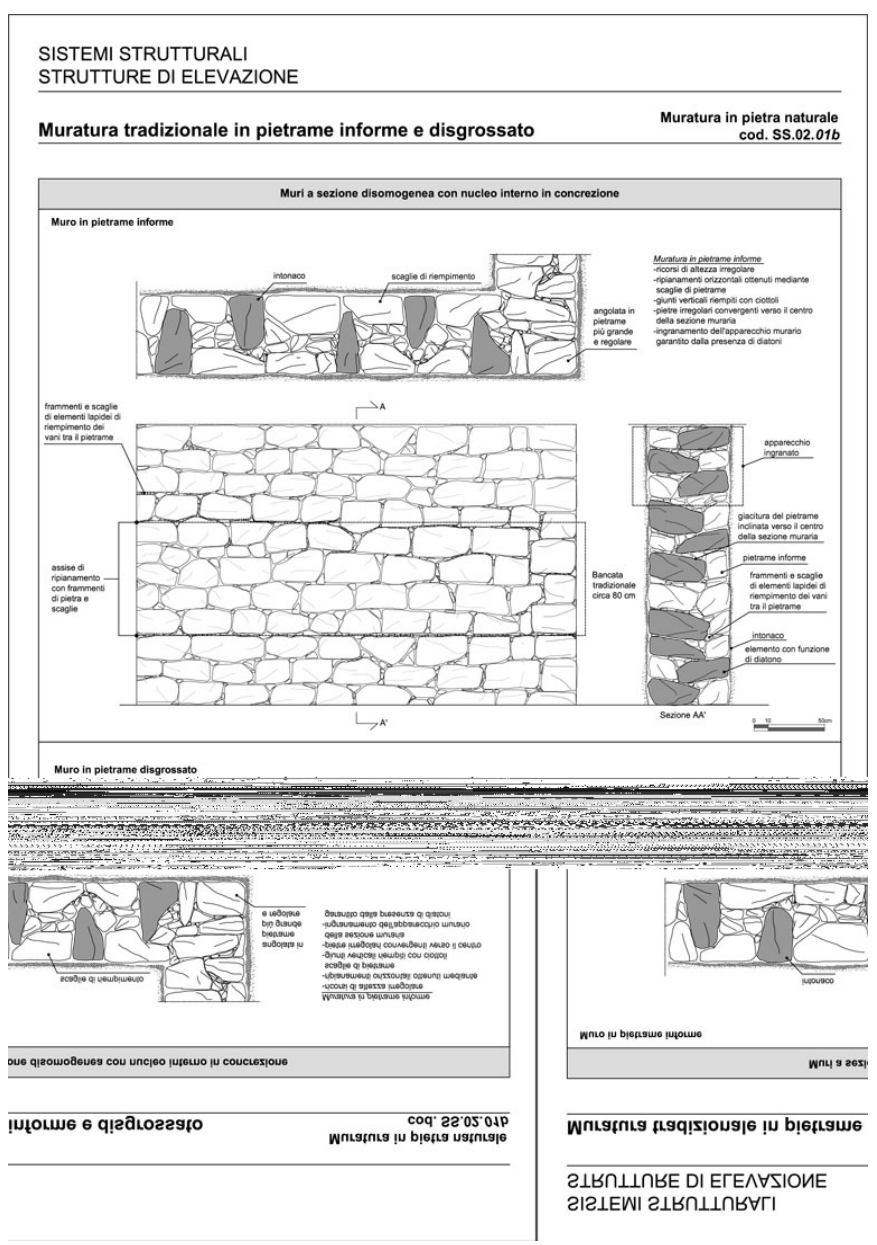

Fig.9 Evolución de los instrumentos... (cit. fig. 8). Composición de los materia- les que componen el muro típico de la arquitectura menor italiana, en piedra rústica acoplada. [Ficha gráfica cod. SS.02.01b]. PUGLIANO, A.: Elementi di...(op. cit).

considerada como una recopilación de modelos de comportamiento proyectivo útiles para la práctica profesional de los operadores y para su formación. Por otra parte, el proyecto contribuirá con seminarios y stage para prácticas, organizados por la Universidad junto con otras Instituciones, actividad formativa que acompañará el desarrollo del proyecto, realizando un efectiva obra - escuela.

En otro orden de cosas, la difusión trata de impulsar de manera específica y útil, una cohesión científica más amplia de rango internacional. Por tanto, el programa concluye con amplios acuerdos de colaboración con patrocinadores europeos seleccionados, interesados en contribuir a la confrontación e intercambio de experiencias respecto a la valorización, tanto de los recursos del territorio, como de la restauración arquitectónica y de sitios de interés arqueológico.

- Características generales de programa.

El proyecto de búsqueda, actualmente operativo, tiende a alcanzar tres objetivos: Principalmente se propone producir, organizar y divulgar un repertorio, lo más extenso posible, de fuentes indirectas (bibliográficas, documentos de archivo, imá- genes...) y de fuentes directas (levantamientos, restituciones gráficas y fotográficas) útiles para documentar la consistencia histórica y material del sitio arqueológico de la Antigua Ostia; además, pretende realizar bases científicas para el ejercicio de la práctica de la conservación.

El segundo objetivo deriva de la comprensión del primero. La recopilación de información amplia y ordenada, hace posible la programación de una serie de ini- ciativas conservadoras, técnicas y proyectivas, necesarias para el desarrollo de la práctica de mantenimiento y restauración. 


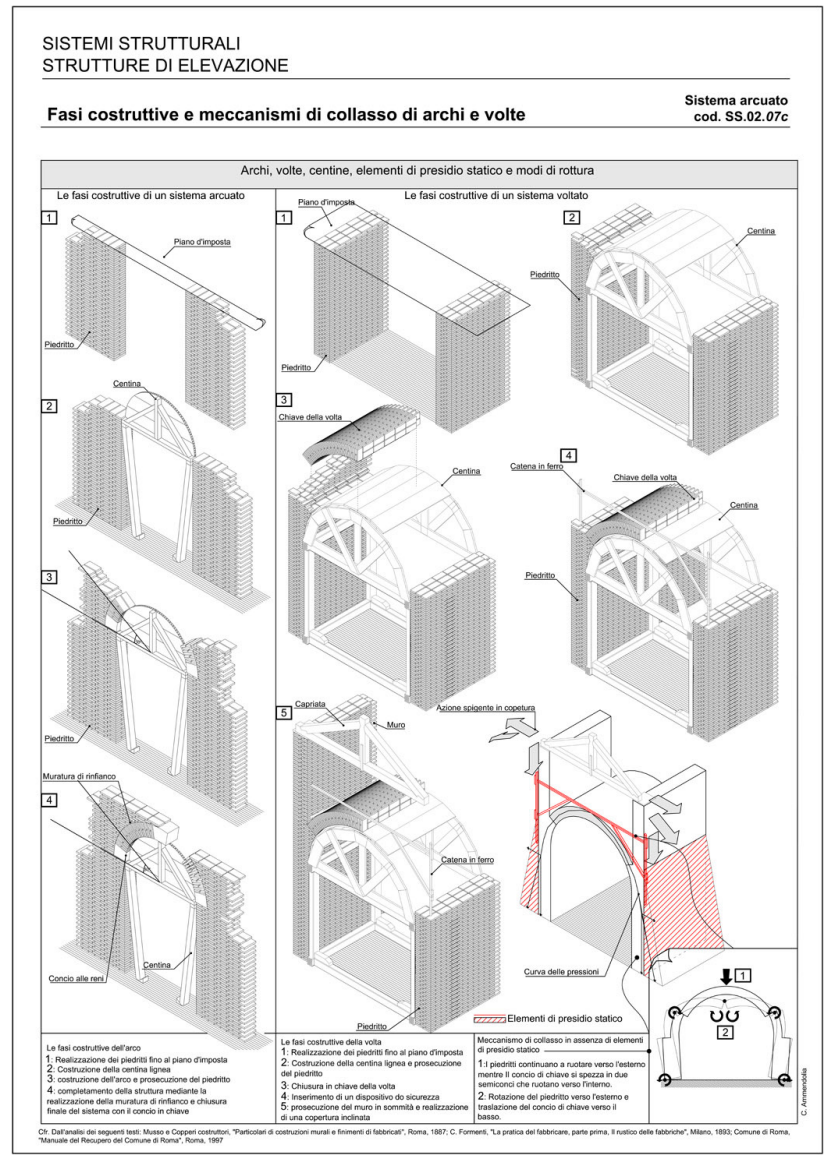

Fig.10 Evolución de los instrumentos... (cit. fig. 8). Composición de los materiales que componen el muro típico de las estructuras con arcos en priedra tallada o en ladrillo; fases de construcción, métodos históricos de dimensionamiento y su relativo commportamiento mecanico [Ficha gráfica cod. SS.02.01b]. PUGLIANO, A.: Elementi di...(op. cit).

El tercer objetivo, sobre la base del conocimiento organizado, consiste en la programación de una serie de iniciativas científicas, artísticas y de gestión, necesarias para el desarrollo de actividades de valorización que sean funcionales para una mejor utilización por parte de especialistas y visitantes.

A los anteriores objetivos se le agrega un cuarto, que resulta producto de los tres anteriores: el proceso de definición de los contenidos del Programa, que se trata en realidad, de un proceso de formación de figuras profesionales expertas en materia de documentación y de conservación del patrimonio arqueológico característico del sitio arqueológico de la Antigua Ostia. Dichos expertos representan pues, el capital humano, es decir, aquellos de los que puede depender la eficacia de la iniciativa en términos de durabilidad y eficacia operativa.

En lo que respecta al primer objetivo, se procederá al reconocimiento de las fuentes citadas, implementándolas eventualmente con mucha atención y con un apropiado equipo de levantamiento. Los datos cognoscitivos serán organizados de manera correcta, de este modo se experimentarán también métodos de catalogación y tratamiento sintético "ad hoc".

Para el segundo objetivo, se procederá a identificar los criterios y la modalidad técnica de intervención más adecuada para las diversas condiciones en que se encuentran las construcciones y los componentes urbanos, sobre la base de sus más evidentes características morfológicas y tipológicas, y naturalmente, de su estado de conservación. En resumen, se trata de puntualizar criterios y experimentar una metodología y un procedimiento de análisis e intervención, útiles para obtener un modelo de comportamiento de calidad, tanto en términos de documentación, como en términos de proyección de las intervenciones técnicas, y así llegar a la definición de unas apropiadas líneas de operación, referidas a la práctica y a la gestión de la conservación. Dichos criterios deben ser graduales, partiendo de la perspectiva de la minima intervención, y eminentemente, del mantenimiento, hasta considerar 


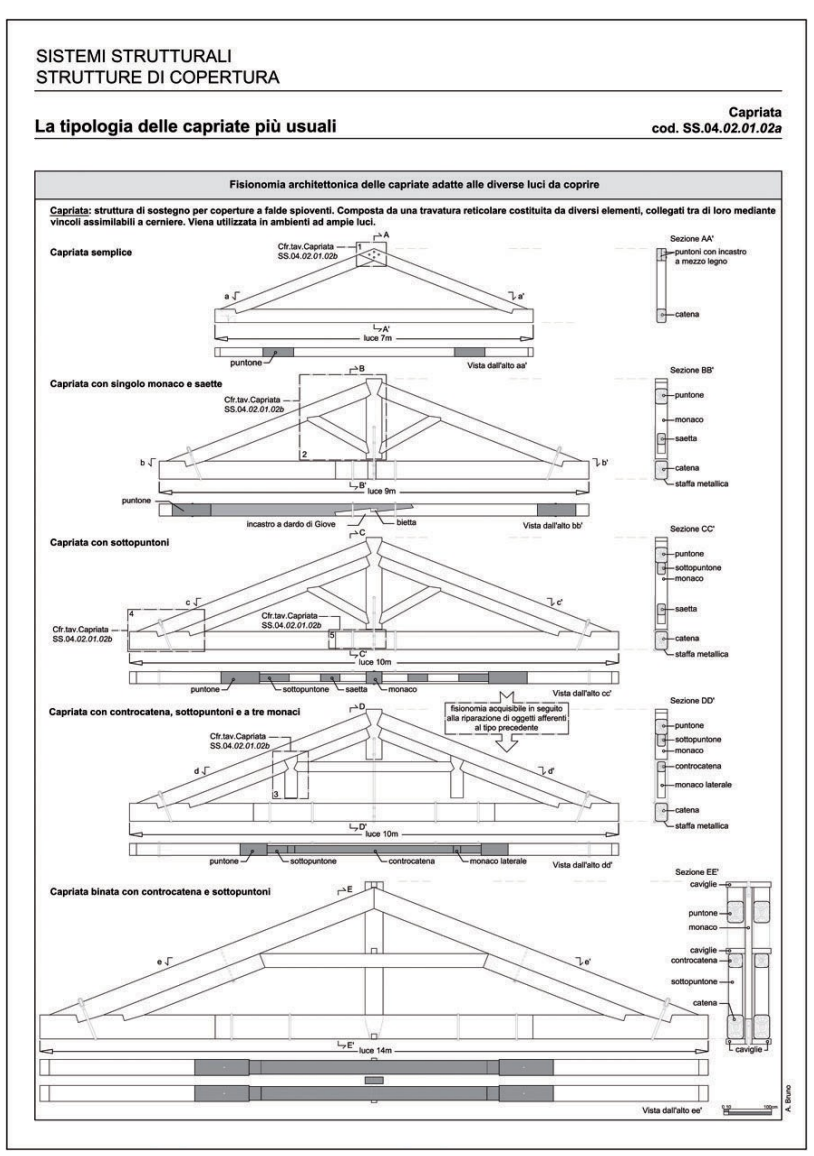

Fig.11. Evolución de los instrumentos... (cit. fig. 8). Tipos de cerchas en las cubier- tas inclinadas con estructura en madera. [Ficha gráfica cod. SS.04.02.01.02a]. PUGLIANO, A.: Elementi di...(op. cit).

intervenciones más extensas y articuladas útiles para la ejecución de proyectos de restauración de carácter arquitectónico.

El tercer objetivo, busca interpretar los datos cognoscitivos explicados anteriormente con el fin de organizar la trama de relaciones e informaciones, valores y significados particulares, que se muestran de forma exhaustiva y evidente como dis- tintivo del contexto material de referencia. En la práctica, se trata de hacer realidad la estructura de un museo abierto y difundido, donde articular una red de recorridos temáticos visitables, así como de su continuo mantenimiento cultural, entendido como una reordenación y actualización científica de la información ofrecida. Sobre esta red se estructuran también las intervenciones de restauración, con el fin de valorizar los monumentos y sus contextos, los cuales tienen un papel particularmente expresivo y/o la particularidad de albergar eventos (exposiciones, representaciones teatrales) que den vida al museo.

Por lo tanto, el Programa nos indica lo necesario para garantizar la conservación de las construcciones a través de una eficaz práctica de mantenimiento, y aquello que se considera útil, para contribuir a la comprensión arquitectónica y física de las edificaciones en función de una correcta y fácil lectura.

Todo lo expuesto anteriormente constituye una gran responsabilidad cultural de carácter multidisciplinar, orientada a la producción y síntesis de la información para el conocimiento, traduciéndose en opciones operativas para proyectos ejemplares.

- Objeto del Programa.

El objeto del análisis y de la sintesis contenidos en el Programa constituyen las singulares edificaciones de la Antigua Ostia, que, si bien estudiadas individualmente, vienen consideradas en su contexto ambiental y en relación con su entorno urbano. El programa no puede prescindir, por tanto, de la organización y del desarrollo coherente de estudios profundos que tengan en cuenta, tanto la lectura material a través del levantamiento, como 


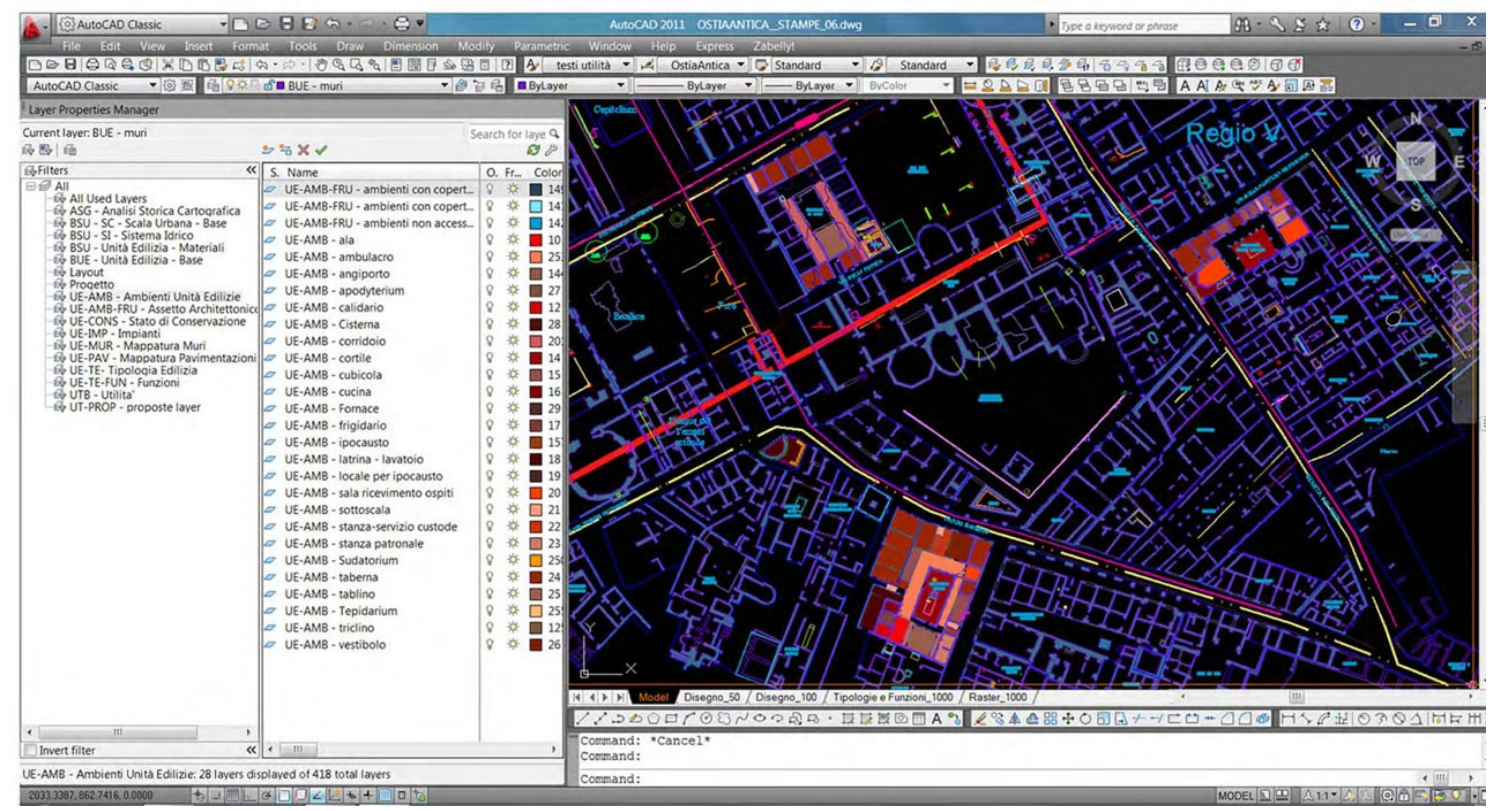

Fig. 12. Formas organizadas de conocimiento y su uso con el fin de conservar y valorizar. Plataforma digital GIS de Ostia Antigua. Visualización de los datos relativos a la caracterización y localización de las antiguas instalaciones hídricas urbanas. Elaborado por Alessandra Di Tommaso para el Programma di azioni integrate di ricerca e formazione per la Documentazione e la Valorizzazione del Sito di Ostia Antica. Universidad "Roma Tre" DiPSA-MiBAC Soprintendenza Speciale ai Beni Archeologici di Roma. Convenzione Quadro. Responsabls: por el DiPSA A. Pugliano; por el MiBAC: A.M. Moretti, A.Pellegrino, M.Merelli, G. Arciprete

el conocimiento de los procesos formativos de la ciudad y de los organismos arquitectónicos construidos con sus diversas connotaciones tipológicas y tecnológicas.

Desde este punto de vista, resulta conveniente volver a consultar el repertorio de fuentes históricas constituidas por la documentación y por las síntesis gráfica textual producidas en el tiempo, a partir de lo ya elaborado en los equipos de excavación sistemática. Las iniciativas para programar, se basan en la coexistencia equilibrada de dos disposiciones entre ellas complementarias: una, orientada principalmente a la conservación de los componentes materiales y artísticos originales; la otra, referida a la atención particular de la documentación y la valorización del significado histórico y arquitectónico de las edificaciones.

La condición descrita impone, que las intervenciones de carácter conservativo relativas a la materia auténtica, deban ser asociadas a las aplicaciones y al desarrollo de actividades de estudio y documentación, útiles para la comprensión profunda de los organismos arquitectónicos originarios y de su propia transformación. Las adquisiciones cognoscitivas maduradas, podrán abrir espacio a la realización de recomposiciones parciales que, además de garantizar con eficacia la salvaguardia del conjunto material, desarrollarán una función didáctica fundamental para la información de los visitantes, los cuales seguirán un recorrido organizado en el lugar. Por lo tanto, tras darle forma a los vestigios, podrán ser reconocidas las característi cas distributivas de algunas de las casas, su volumetría y sus dotaciones tipológicas. Tal conocimiento podrá, en su caso, dar lugar a reconstrucciones parciales que tendrán en cuenta las características tipológicas como: impluvium, atrios y jardines, escaleras, y cualquier elemento cerrado que sea apropiado para demostrar, tanto la jerarquía, como las diversas disposiciones de los ambientes de la casa. En definitiva, se deberá procurar darle 


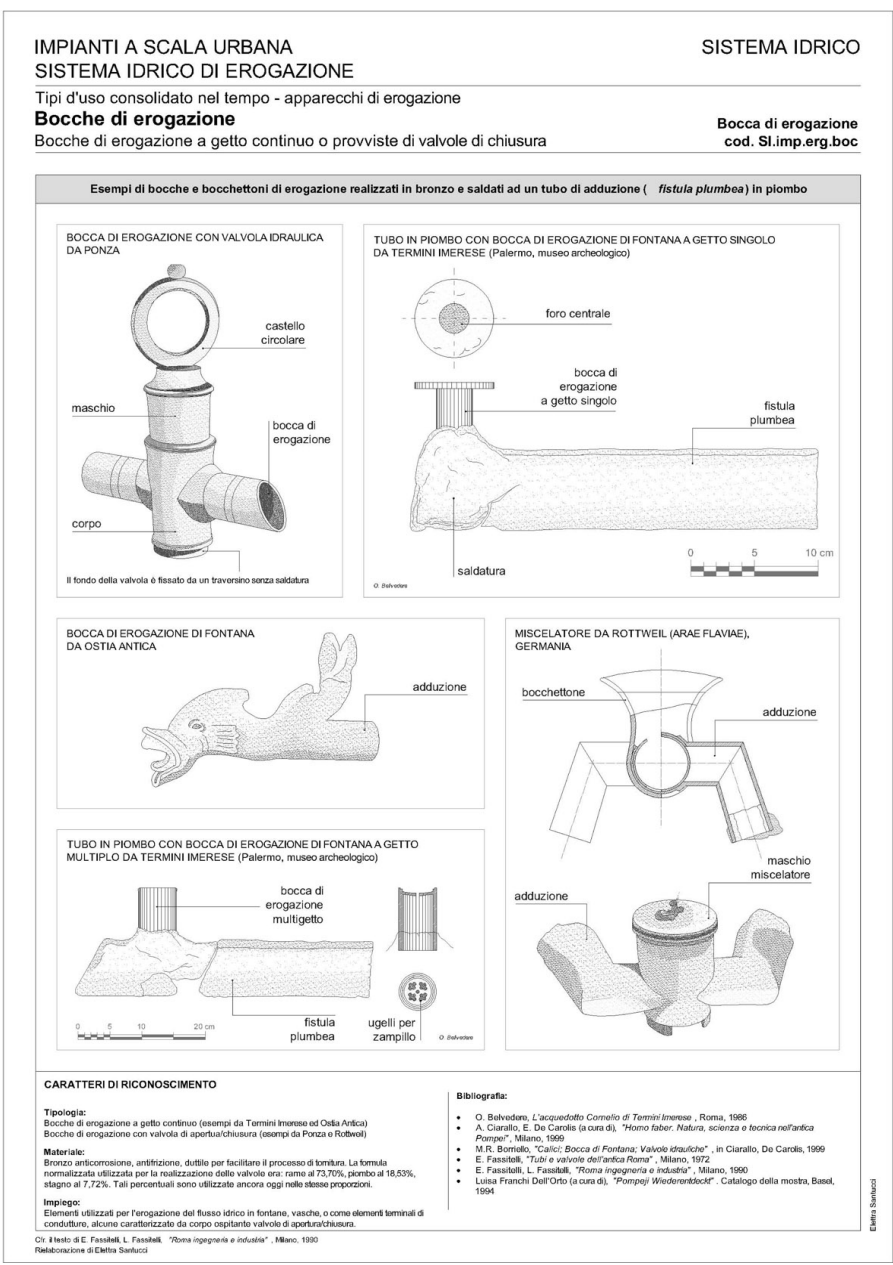

Fig.13.Instrumentos para el reconocimiento del valor de los antiguos componentes materiales de Ostia. El glosario de compilación del Banco de Datos GIS para Ostia Antigua. Los aparatos metálicos para verter en las antiguas instalaciones bidricas urbanas. [Ficha gráfica cod. SI.imp.erg.boc]. Elaborado por Elettra Santucci para el Programma di azioni integrate di ricerca e formazione per la Documentazione e la Valorizzazione del Sito di Ostia Antica. Universidad "Roma Tre" DiPSA- MiBAC Soprintendenza Speciale ai Beni Archeologici di Roma. Convenzione Quadro. Responsables: por el DiPSA A. Pugliano; por el MiBAC: A.M. Moretti, A.Pellegrino, M.Merelli, G. Arciprete

cuerpo, en el tiempo, a las adquisiciones científicas derivadas de un estudio profundo sobre las características arquitectónicas de las casas, en la perspectiva de una progresiva y eficaz recomposición, al menos ideal.

- Actividad de Conservación de la Materia Auténtica.

Las intervenciones que tienen como objeto la conservación de la materia auténtica, en vista del complejo mantenimiento de la fisonomía actual del monumento arquitectónico, consisten en una intervención con un tipo de restauración artística, localizada y puntual, de fuertes especificaciones técnicas. Dichas intervenciones están dirigidas al contexto material donde sea absolutamente destacada la presencia artística, y también con mayor frecuencia, irán aplicadas a los vestigios materiales que deben ser transmitidos al futuro mediante la actividad de mantenimiento programado. Dichas intervenciones se basan en el uso de materiales y técnicas de mínimo impacto tecnológico, reversibles y compatibles con el contexto material original. El problema de la extrema degradación de los componentes de las construcciones descubiertas y privadas de mantenimiento, imponen sin embargo, la necesidad de intervención con episodios de reintegraciones, convenientes para proporcionar la debida conservación de los elementos arquitectónicos decorados, introduciendo el tema de las intervenciones destinadas a la conservación de los significados arquitectónicos presentes en la materia auténtica. El programa, junto con la observación de la dinámica del proceso de degradación y organización de la prevención, y del cuidado oportuno de los fenómenos irreparables, prevé el desarrollo del análisis de carácter histórico, tipológico y tecnológico, eficaz para la aplicación en un mismo proyecto, y también, del análisis del 
sistema de elementos de recomposición destinados a la protección. Estos últimos, por lo tanto, deberán estar dotados de los requisitos de eficacia funcional y mecánica, y ser controlados para su efectividad y garantía filológica y tipológica.

- Actividad de Reintegración y Restauración con fines de valorización.

Se trata de intervenciones dirigidas a la recomposición, más o menos extendida en las obras constructivas, con los fines conservativos citados, pero también con el propósito de una mejor lectura de su estratificada fisonomía arquitectónica. Naturalmente, es conveniente prever la aplicación de dichas intervenciones en contextos materiales, para los cuales sea oportuna, y posible, delinear hipótesis reconstructivas de calidad, (es decir, verificadas y profundizadas hasta el nivel del detalle contructivo). Dichos contextos materiales, serán al mismo tiempo, seleccionados en base a su garantía tipológica y a la capacidad funcional y de usos para los cuales podrán ser destinados. Asignar un destino de uso apropiado al monumento, es la precuanto evita su abandono futuro tras su restauración, garantizando con el uso su conservación, gracias a una continua y concienzuda manutención. Por el contrario, no parece oportuno proceder a la intervención del género descrito, en ausencia de un programa orgánico para la utilización del bien. En este caso particular, los contextos en los que se considera oportuno efectuar este tipo de intervención, podrían constituir los puntos estratégicos de información en los recorridos principales.

- Tipología de las intervenciones de la restauración arquitectónica

La tipología de las intervenciones de la restauración arquitectónica comporta: beneficios, mejoras, protección de lo existente e intervención a través de la recomposición de elementos arquitectónicos funcionales y de acabado. Dichas intervenciones se realizan sobre los organismos arquitectónicos e involucran las estructuras de sus muros, de la cubierta, de los entrepisos y de las escaleras. Se consideran, naturalmente, intervenciones absolutamente reconocibles y reversibles, dotadas de gran connotación didáctica, con el objetivo de evidenciar algunas expresiones de la cultura material que ha producido tal arquitectura. Éstas derivan del conocimiento documental arqueológico adquirido sobre un simple monumento, y del éxito de análisis de carácter tipológico y comparativo, pertinentes a la disciplina de la arquitectura.

\section{- La durabilidad del éxito del programa. La formación de los "actores" de la} conservación.

La reversibilidad es imprescindible, ya que en la sistematización actual, representa el estado del conocimiento en el momento presente y debe permitir la inclusión de una actualización en un futuro. Tal perspectiva indica el papel de la didáctica de la arquitectura, que tiende a alimentar el estudio científico, relativo a la cultura material y a las antiguas técnicas de construcción, y también útiles para la formación de estudiosos y proyectistas que se dediquen a la práctica de la conservación y de la restauración. Actualmente, para el desarrollo de este aspecto del Programa, se está procediendo desde estudios preliminares de factibilidad, a la creación de una Escuela de Especialización postlaurea (posgrado), en función de organizar y gestionar el mantenimiento cultural de tal iniciativa. Dicha didáctica, especializada y profesionalizada, deberá tener un carácter aplicativo y no se limitará a simular procesos cognoscitivos y simples síntesis proyectuales, por el contrario, se centrará en casos reales de estudio y podrá contribuir con la producción analítica y con proyectos auténticos y válidos, al igual que mediante la conservación de los mismos. 